\title{
Mitf from neural crest to melanoma: signal transduction and transcription in the melanocyte lineage
}

\author{
Colin R. Goding ${ }^{1}$ \\ Eukaryotic Transcription Laboratory, Marie Curie Research Institute, The Chart, Oxted Surrey, RH8 OTL UK
}

Perhaps the most obvious manifestation of the complex interplay between environmental cues, signal transduction pathways, and transcription factors underlying the genesis and differentiation of a cell lineage is provided by the enormous diversity of genetically determined pigmentation patterns. Because melanocytes, the cells responsible for skin, hair, and eye color, are dispensable for viability, the highly visible consequences of mutations affecting the melanocyte lineage (Fig. 1) has allowed over 90 independent genes to be implicated in the genesis of mouse coat color (Mouse Genome Informatics: http:// www.informatics.jax.org//. The 30 or so of these genes that have been cloned to date (http://www.cbc.umn. edu/ifpcs/micemut.htm) not only encode proteins required for the manufacture of the pigment melanin and the function of the melanosome, but also encode signaling molecules and transcription factors that play critical roles in the development of the melanocyte lineage. This unusually large genetic resource which extends to a wide variety of species has made the regulation of melanocyte development an attractive system for understanding how the coordination of gene expression required for the commitment and differentiation of a specific cell lineage is achieved.

Melanocytes originate as nonpigmented precursors termed melanoblasts in the mouse neural crest at around embryonic day 10.5 (E10.5), and following migration and proliferation reach the limb buds by E12 and enter the epidermis at the level of the lateral trunk by E13/E14 (Mayer 1973). Melanocytes are found as mature pigment cells in the skin and hair follicles, as well as a range of other sites where their role as pigment-producing cells is less understood. Thus, melanocytes are present in the choroid layer of the eye, the Harderian gland, the anal canal, and in the stria vascularis of the inner ear where they are crucial for hearing because they play a vital role in the endolymph-controlled generation of action potentials (Steel and Barkway 1989; Tachibana 1999). The effects of mutations affecting genes playing a key role in the melanocyte lineage may therefore be manifest at several levels: Mutations may affect genes required for dif-

${ }^{1}$ E-MAIL c.goding@mcri.ac.uk; FAX +44 1883714375. ferentiation-specific functions such as the genesis of pigment, or more interestingly from the developmental perspective, any step from the specification and commitment to the melanocyte lineage, to the survival, proliferation, and migration of melanoblasts from the neural crest.

Interest in the melanocyte system is also afforded by the impact on melanocytes of ultraviolet (UV) light. In humans, epidermal melanocytes respond to UV irradiation by increasing the synthesis of melanin in membrane-bound structures termed melanosomes that are transferred to surrounding keratinocytes, a process known as the tanning response. At least one role for melanin is likely to be in protection against UV-induced DNA damage (Hill 1992). The incidence of UV-induced DNA damage, however, correlates with the risk of transformation of the melanocyte to a malignant melanoma, an aggressive and increasingly common form of cancer for which a proportion of the population have a genetic predisposition. The difficult path towards understanding the molecular and genetic basis of the progression from a melanocyte to a malignant melanoma has been made easier with recent observations that link the genesis of melanoma to deregulation of pathways operating in melanocyte development.

The aim of this review is to provide an overview of how gene expression in neural crest-derived melanocytes is controlled by the interplay between specific transcription factors and signal transduction pathways. Because of limitations of space, the review focuses on the regulation of the expression and function of the Microphthalmia-associated transcription factor, Mitf. For the same reason, the development of the retinal pigment epithelium (RPE), the pigmented layer of cells lying immediately behind the retina which arises via differentiation of the posterior part of the optic cup, is not discussed.

\section{The microphthalmia-associated transcription factor}

Ten years ago, virtually nothing was known about how the program of gene expression underlying the genesis of the melanocyte lineage was regulated. The isolation of the genes encoding the melanocyte-specific melanogenic 

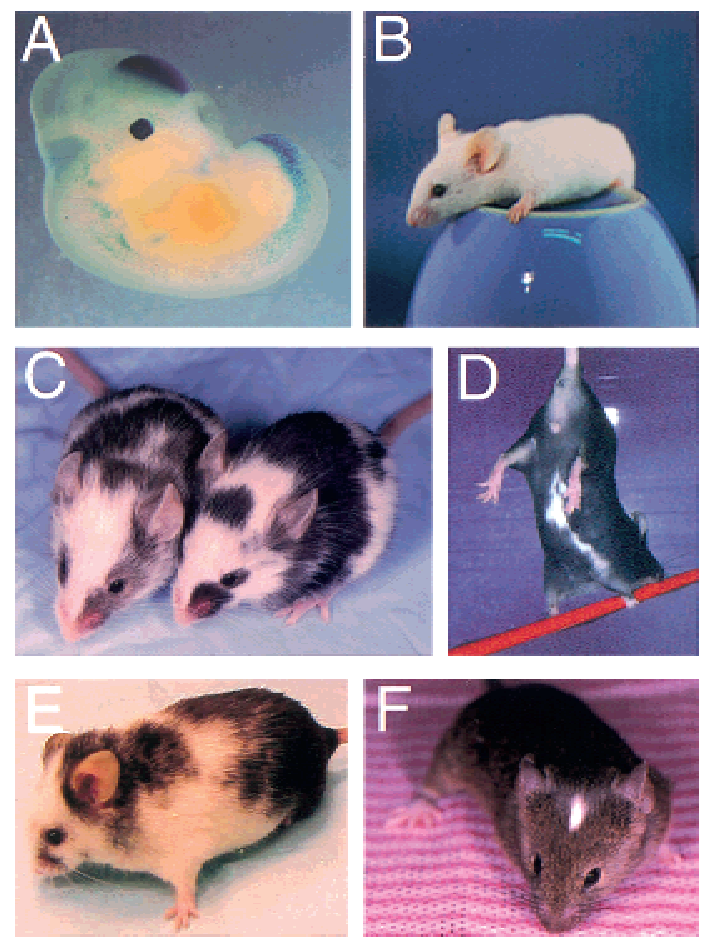

Figure 1. Mutations in the genes encoding key signaling molecules or transcription factors result in characteristic coat color phenotypes. (A) An E12.5 transgenic embryo expressing LacZ under control of the Dct promoter. In addition to strong staining in the telencephalon, Dct-positive melanoblasts migrating away from the neural crest are readily apparent. (B) A Mitf $f^{m i-b w}$ mouse characterized by an insertion of an L1 line element in intron 3 of the Mitf gene specifically disrupts expression of the Mitf-M isoform (Yajima et al. 1999) leading to loss of neural crest-derived melanocytes. As the Mitf isoforms expressed in the RPE function normally, the outcome is a black-eyed white phenotype. (C) An Mitf vga-9/mi-sp compound heterozygote resulting from a cross between a Vga-9 homozygote (a null mutant for Mitf) and an Mitf ${ }^{m i-s p}$ homozygote. Vga-9 homozygotes are white, whereas the heterozygotes have normal pigmentation. Both Mitf ${ }^{m i-s p}$ homo- and heterozygotes are pigmented normally despite the fact that this allele prevents expression of the Mitf(+) isoform. In the compound heterozygote shown, the white patches result from loss of melanoblasts and reveal a requirement for the expression of the Mitf(+) isoform in this genetic background. The cross was performed in the laboratory of Heinz Arnheiter. (D) A Pax3 heterozygote exhibiting a char-

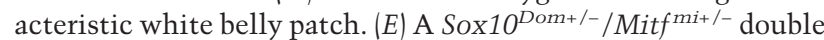
heterozyogote. Neither Sox $10^{D o m}$ heterozyogotes nor Mitf $f^{m i}$ heterozygotes exhibit any marked pigmentation phenotype. In contrast, enhanced loss of melanocytes resulting in extensive hypopigmentation is observed in the double heterozygote shown (Potterf et al. 2000), reflecting the ability of Sox10 to regulate Mitf expression. (F) The animal shown is a heterozygote at the Kit locus resulting from the transgenic insertion of a LacZ reporter gene as described (Bernex et al. 1996). The heterozyogotes exhibit a white forehead and belly patch.

enzymes tyrosinase and tyrosinase-related protein-1 (Tyrp-1), allowed the characterization of the promoter elements driving melanocyte-specific gene expression. It was anticipated that this approach would lead to the identification of melanocyte-specific transcription factors that regulated the expression of these differentiation markers and, in the long term, would yield insights into the regulation of these genes by signal transduction pathways. Moreover, because tyrosinase, Tyrp-1, and the other melanogenic enzymes act together within the melanosome to generate pigment, it was anticipated that their expression would be coordinated by transcription factors binding to elements shared between their respective promoters, and that at least some of these transcription factors might also play a role in the development of the melanocyte lineage. The analysis of the tyrosinase and Tyrp-1 promoters appeared to fulfill this prophecy. Both promoters shared a common 11-bp element AGTCATGTG termed the M box (Lowings et al. 1992), which was required for their expression. Importantly, the core CATGTG (E box) motif within the $M$ box was known to bind members of the basic-helix-loop-helix (bHLH) and bHLH-leucine zipper (bHLH-LZ) families of transcription factors. The identification of the M box as an element conserved in melanocyte-specific promoters was complemented by the isolation of the gene encoding the Microphthalmia-associated bHLH-LZ transcription factor Mitf (Hodgkinson et al. 1993; Hughes et al. 1993). The isolation of this gene, which will be referred to throughout as Mitf irrespective of species of origin, was a turning point in understanding the molecular mechanisms underlying melanocyte development.

Mice bearing null alleles of the Mitf gene exhibit a loss of neural crest-derived melanocytes and associated deafness, and a failure of RPE differentiation (Moore 1995), while in the zebrafish a null mutation in an Mitf gene, nacre, results in loss of melanophores but does not affect the RPE (Lister et al. 1999), perhaps implying the existence of additional Mitf-like genes in this species. The importance of Mitf as a determining factor in melanocyte development was underlined when it was shown that expression of Mitf in fibroblasts conferred on the recipient cells characteristics of melanocytes (Tachibana et al. 1996), although the fibroblasts used in this experiment were unusual in that they were able to express the Dct (Tyrp-2) gene even before ectopic expression of Mitf. Similarly, ectopic expression of Mitf can induce transdifferentiation of neuroretina into melanocytes (Planque et al. 1999), and missexpression of zebrafish Mitf resulted in ectopic melanized cells (Lister et al. 1999). Thus, it would appear that in some cells at least the expression of Mitf is sufficient to establish a program of melanocyte-specific gene expression.

The Mitf gene that spans over $50 \mathrm{~kb}$ in the mouse (Hallsson et al. 2000; Udono et al. 2000) encodes a positively acting transcription factor containing a transcription activation domain and a bHLH-LZ domain that mediates DNA-binding and dimerization. Both the transcription activation and bHLH-LZ domains are highly conserved in the closely related TFE3, TFEB, and TFEC transcription factors, and not surprisingly Mitf can form heterodimers in vitro with these proteins (Hemesath et al. 1994), but not with other bHLH-LZ factors such as Myc, Max, or USF. Notwithstanding the in vitro asso- 
ciation with other members of the Mitf subfamily of bHLH-LZ factors, TFE 3 and TFEB are absent from the neural crest at times when the effects of Mitf mutations become apparent (Nakayama et al. 1998), indicating that Mitf may function as a homodimer during development of the melanocyte lineage. Indeed, even in B16 melanoma cells where TFE3 is expressed, it fails to coimmunoprecipitate with Mitf and endogenous TFE3 does not appear able to bind the M-box, despite being able to activate transcription from an M-box containing reporter if overexpressed (Verastegui et al. 2000). These results indicate that at least in the melanocyte lineage, the ability of Mitf to form heterodimers with TFE3 may be limited and that the capacity of TFE3 and other related factors to regulate transcription may be tightly controlled by as yet unidentified factors. In common with other bHLH-LZ transcription factors, Mitf can bind in vitro so-called $\mathrm{E}$ box elements with the generic sequence CATGTG or CACGTG and many of the Mitf mutations affecting mouse coat color that have been characterized to date affect the ability of Mitf either to bind DNA or to dimerize (Hemesath et al. 1994; Steingrímsson et al. 1994).

The characterization of the Mitf gene has led to the intriguing observation that Mitf is expressed as multiple isoforms, termed Mitf-M, Mitf-A, Mitf-H (for review, see Yasumoto et al. 1998), and Mitf-C (Fuse et al. 1999). These isoforms share common transcription activation and DNA-binding domains, but differ in the amino-terminal amino acids encoded by exon 1. The unique amino-termini of the Mitf-M, Mitf-A, Mitf-C, and Mitf-H isoforms implies that they are transcribed from different promoters, the relative locations of which are currently being determined (Hallsson et al. 2000; Udono et al. 2000). Whether the different amino-terminal regions of these Mitf isoforms confer distinct properties on each protein, or whether they simply reflect the fact that the correct temporal and spatial expression of Mitf can only be achieved using different promoters is not known. Expression of Mitf-M is restricted to neural crest-derived melanocytes and is absolutely required for the development of these cells because the insertion of an L1 transposable line element into intron 3 of the Mitf gene in the Mitf $^{\text {mi-bw }}$ mouse specifically disrupts Mitf-M expression and leads to a black-eyed white phenotype (Yajima et al. 1999) (Fig. 1B). Mitf-A is expressed more widely is enriched in the RPE, and is anticipated to play a key role in RPE formation. The Mitf-C and the so-called "heartform" Mitf-H, are widely expressed at low levels and it is not yet clear whether these isoforms are functionally significant.

One of the most enigmatic features of Mitf is the presence of two differentially spliced forms, which differ only with respect to an internal six amino acids found uniquely in the so-called Mitf $(+)$ isoform (Hodgkinson et al. 1993; Steingrímsson et al. 1994). How the $(+)$ and $(-)$ forms might confer distinct properties on Mitf in vivo has been the subject of considerable speculation but remains for the time being an unresolved question. Both the Mitf-M and Mitf-H isoforms are expressed as (-) and $(+)$ versions (Hallsson et al. 2000) and it is likely that alternative splicing of this region will be a feature of all Mitf isoforms. Genetic evidence lends support to the idea that expression of the distinct $(+)$ and $(-)$ forms of Mitf is important. Mice homozygous for the Mitf ${ }^{m i-s p}$ allele have a mutation which interferes with the production of the Mitf(+) isoform, resulting in the expression of Mitf(-) only (Steingrímsson et al. 1994). Despite the absence of the Mitf(+) isoform, Mitf $f^{m i-s p}$ homozygotes are normally pigmented (Wolfe and Coleman 1964), although tyrosinase activity is marginally reduced. However, when heterozygous with other Mitf mutant alleles, Mitf ${ }^{m i-s p}$ can exert a significant effect. For example, Mitf ${ }^{\text {va-9 }}$ homozygotes (Mitf null) are white and the heterozygotes have normal pigmentation, while Mitf ${ }^{m i-s p}$ homo- and heterozygotes are normally pigmented. In contrast, in the Mitf $f^{\text {va-9/mi-sp }}$ compound heterozygote shown in Figure 1C, the white patches result from loss of melanoblasts and reveal a requirement for the expression of the Mitf(+) isoform in this genetic background. A requirement for the Mitf(+) isoform is also revealed in culture where the survival of melanocytes derived from Mitfmi-sp homozygous mice is severely suppressed (Boissy and Lamoreux 1995). Precisely what role is played by the $(+)$ and $(-)$ forms is unclear because in vitro both the $(+)$ and the $(-)$ isoforms bind DNA with similar steady state affinities, though the rate of dissociation of the Mitf(-) isoform is enhanced (Hemesath et al. 1994). Possibly, the two isoforms participate differentially in interaction with as yet uncharacterized Mitfinteracting proteins or facilitate differential regulation of Mitf.

\section{Regulation of Mitf expression in neural crest-derived melanocytes}

Mitf is the earliest known marker of commitment to the melanocyte lineage. Intriguingly, the appearance of melanoblasts expressing Mitf mRNA and their survival for $\sim 48 \mathrm{hr}$ is independent of a functional Mitf protein (Opdecamp et al. 1997). Once expression is established, however, continued expression of Mitf is clearly essential if melanoblasts are to persist $>2$ days. Given the absolute importance of Mitf, it is not surprising that at different stages in melanocyte development, Mitf activity or expression levels are regulated. The analysis of the promoter-driving expression of the Mitf-M isoform in neural crest-derived melanocytes suggests that the onset of Mitf-M expression may be dictated by an array of cooperating transcription factors acting coordinately to raise Mitf expression above a critical threshold. The transcription factors implicated to date in regulation of the Mitf promoter include Pax3, CREB, Sox10, and Lef1 (Fig. 2A), with each factor able to confer on the Mitf promoter the capacity to respond to specific signals. The link between Mitf expression and Pax3, Sox10, and Lef1 is underscored by the genetics which link mutations in each of these genes to loss of melanoblasts and in the case of $P A X 3$ and $S O X 10$, to syndromes characterized by pigmentation defects. 
A

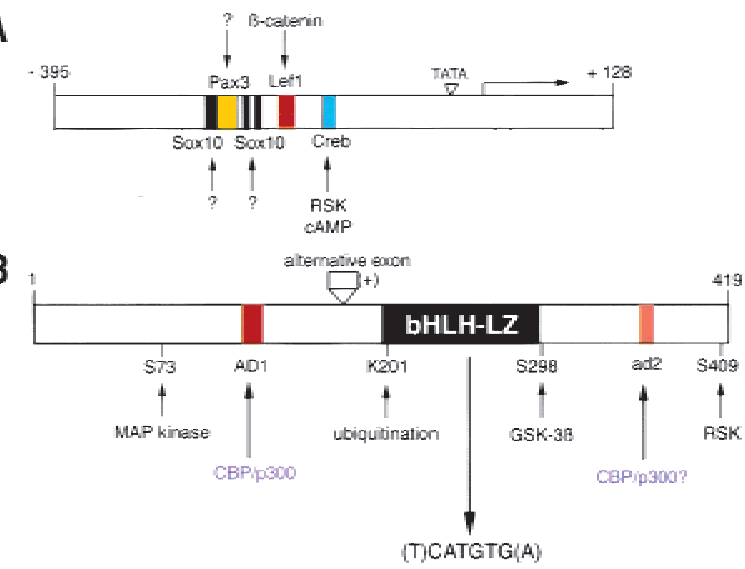

Figure 2. (A) The murine Mitf promoter and regulation of Mitf expression. The onset of Mitf expression characterizes commitment to the melanocyte lineage and four transcription factors are known to date that regulate expression of the neural crest-specific Mitf-M isoform, namely Sox10, Pax3, CREB, and Lef1. The relative positions of the binding sites for these factors within the proximal Mitf promoter is shown and it is likely that additional regulators will be identified in the future. Although no information is available on the regulation of Pax3 or Sox10, CREB can be phosphorylated by a number of kinases including p90 Rsk, which lies downstream of the MAP kinase pathway and receptor tyrosine kinases, and MAPKAP-K2 which is stress responsive via the p38signaling pathway. MSH interaction with the Mclr can elevate cAMP levels that in melanocytes can also activate the MAP kinase pathway, resulting in elevated Mitf promoter activity. CREB knockout mice have no coat-color phenotype, most likely because its role may also be performed by a number of other related factors with similar DNA-binding and regulatory properties. The Lef1 transcription factor is responsive to Wnt signaling through its interaction with $\beta$-catenin. Both Sox 10 and Pax3 are widely expressed in the neural crest and CREB and Lef1, or related Tcf factors, are also widely expressed. The limited number of neural crest cells that stably express Mitf and are consequently committed to the melanocyte lineage could be accounted for if establishing Mitf expression is a stochastic process. Throughout the neural crest, factors such as Pax 3 and Sox 10 will be competing with nucleosomes for binding to the Mitf promoter. However, only in a few cells will a critical mass of positive regulatory factors receiving the appropriate signals overcome the threshold represented by the nucleosome barrier at the promoter (Yuh et al. 1998). Once Mitf expression is established, it only needs to be maintained throughout the migration and proliferation of the melanoblast population. (B) Regulation of the Mitf protein. Shown is a schematic of the Mitf-M neural-crest specific isoform of Mitf. Mitf is characterized by a bHLH-LZ DNA-binding and dimerization domain which targets (T)CATGTG(A) motifs, an amino-terminal transactivation domain (AD1) which interacts with the transcription adaptor proteins $\mathrm{p} 300$ and CBP. A second putative activation domain (ad2) located in the carboxy-terminal region that may also interact with these co-factors, and a 6-amino acid differential splice form of unknown function. To date Mitf is known to be targeted by three kinases: GSK-3 $\beta$ which regulates Mitf DNA-binding via phosphorylation on S298; the MAP kinase ERK2, which targets S73; and members of the p90 Rsk family of kinases, which can phosphorylate S409. All three kinases can be regulated by the action of receptor tyrosinase kinases such as Kit. The role of phosphorylation by MAP kinase and Rsk appears to be to control Mitf protein levels by regulating its ubiquitination on K201 and subsequent proteosome-mediated degradation.
Regulation of Mitf expression by Pax3 In humans, mutation of the Mitf gene can give rise to Waardenburg syndrome type 2 (WS2) (Tassabehji et al. 1994), which is characterized by pigmentary disorders and hearing loss, reflecting the role of melanocytes in the function of the inner ear. The related syndrome, Waardenburg syndrome type 1 (WS1) is also associated with pigmentation and auditory problems, although in addition, WS1 patients may also exhibit cranio-facial abnormalities. WS1 results from mutations in the gene encoding the PAX3 transcription factor (Tassabehji et al. 1992, 1993; Baldwin et al. 1994). The similarities between WS1 and WS2 in themselves suggest that PAX3 might regulate the expression of Mitf, with the more severe phenotype associated with WS1 being accounted for by the fact that PAX3 has a wider role in the development of the neural crest than Mitf. The likely relationship between Mitf and PAX3 indicated by the genetics, has been substantiated by the observation that Mitf expression is indeed subject to regulation by PAX3 (Watanabe et al. 1998), which is expressed in both melanoblast and melanocyte cell lines (Galibert et al. 1999). Thus, the Mitf promoter is recognized by PAX3 in vitro and in vivo (Watanabe et al. 1998), and mutations within PAX3 that are known to impair its ability to regulate transcription inhibit its capacity to regulate Mitf promoter activity. Although the conclusion that PAX3 is a regulator of the Mitf promoter is based largely on the results from transient transfection assays, it seems likely that PAX3 is responsible, at least in part, for activating Mitf transcription. A dependence of Mitf expression on Pax3 would account for the loss of neural crest-derived melanocytes in splotch mice that bear Pax3 mutations (Fig. 1 D-E). Interestingly, Pax3 not only regulates Mitf expression but has also been implicated in direct regulation of Tyrp-1 expression /Galibert et al. 1999) suggesting that as in muscle cells, Pax3 may perform both differentiation as well as developmental functions in melanocytes.

Regulation of Mitf expression by Sox10 Sox proteins are transcription factors related to the sex determining factor SRY in that they contain a high mobility group type DNA-binding domain. Sox10 is expressed in a wide range of neural crest-derived tissues including both melanocyte and melanoma cell lines (Kuhlbrodt et al. 1998; Southard-Smith et al. 1998). The requirement for SOX10 in the development of the melanocyte lineage was revealed by the observation that SOX10 mutations were responsible for Waardenburg-Hirschsprung disease (Waardenburg syndrome type 4, WS4) in humans, and disrupted neural crest development in the Dominant megacolon (Dom)(Hirschprung model) mouse (Pingault et al. 1998; Southard-Smith et al. 1998). This disease is characterized by a combination of deafness and pigmentary disorders together with aganglionic megacolon and can apparently be caused by mutations that disrupt SOX10 function. Although mutations in the Endothelin-B receptor gene $(E d n r b)$ give rise to a similar phenotype to that characteristic of SOX10 mutations (Baynash et al. 1994; Hosoda et al. 1994; Puffenberger et al. 1994), 
$E d n r b$ is unlikely to represent a target gene as the onset of Ednrb expression coincides with that of Sox10. Conversely, the initiation of Mitf expression occurs soon after that of Sox10. This, together with the enhanced loss of melanocytes seen in Sox $10^{\mathrm{Dom}+/-} / \mathrm{Mitf}^{\mathrm{mi+/}-}$ double heterozygous mice (Fig. 1G) compared to the minimal pigmentation defects observed in Sox $10^{\mathrm{Dom+} /-}$ and Mitf $^{\text {mi+/- }}$ heterozygotes (Potterf et al. 2000) led to the hypothesis that Sox10 might regulate Mitf expression directly. The genetic evidence for an interaction between Sox10 and Mitf, though indirect, is substantiated by the observation that Sox10 can bind at least two sites in the Mitf promoter (Fig. 2A) and activate transcription up to 50-fold in transfection assays (Potterf et al. 2000; M. Lee, J. Goodall, R. Ballotti, and C.R. Goding, in prep.). The link between WS4 and Mitf expression was strengthened further by the fact that Mitf expression is inhibited by the naturally occurring Dom mutation of Sox10, which results in a Sox 10 protein that can bind DNA but which lacks the carboxy-terminal transcription activation domain. The architectural role of the Sox10 DNA binding domain in bending DNA is therefore unlikely to be sufficient to activate the Mitf promoter (Potterf et al. 2000; M. Lee, J. Goodall, R. Ballotti, and C.R. Goding, in prep.).

Although there is no evidence for a direct interaction between Sox10 and Pax3, the proximity of the Sox10 and Pax3 binding sites in the Mitf promoter (Fig. 2A) raises the possibility that the two proteins can act synergistically in activating transcription at the Mitf promoter as has been observed for these proteins in glial cells (Kuhlbrodt et al. 1998). It is nevertheless likely that both Pax3 and Sox10 together play a key role in establishing Mitf expression in cells destined to become melanocytes.

Regulation of Mitf expression by cAMP A common theme among key developmental regulators is that their expression is tightly controlled. While nothing is known as to how Sox10 and Pax3 might act to couple signal transduction pathways to regulation of Mitf expression, the isolation of the Mitf promoter (Fuse et al. 1996) revealed a potential cyclic AMP response element (CRE) at position -147 relative to the transcription startsite (Fig. 2A). The presence of this element prompted speculation that Mitf expression would be modulated by the level of cAMP present in the cell. This speculation was fuelled by the observation that the conserved Mitf target site in the tyrosinase, Tyrp-1, and Dct promoters, the M box, is cAMP-responsive (Bertolotto et al. 1996, 1998b). Consistent with this, the level of Mitf present in the cell, and as a result Mitf DNA-binding activity, is indeed increased in response to elevated cAMP levels (Bertolotto et al. 1996, 1998b). Under the conditions used in these studies, the increase in Mitf protein in B16 melanoma cells that results from the activation of the Mitf promoter through the CRE (Bertolotto et al. 1998a) is transient. Maximal Mitf expression levels are achieved around $3 \mathrm{hr}$ after the addition of forskolin to the cells and by $5 \mathrm{hr}$ is already declining. After $24 \mathrm{hr}$ the level of Mitf protein present in the B16 melanoma cells used is almost returned to basal levels. The transient nature of the activation of Mitf ex- pression explains the puzzle as to why Ganss et al. (1994b) failed to observe cAMP-mediated activation of the mouse tyrosinase promoter; they assayed for tyrosinase promoter activity $48 \mathrm{hr}$ posttransfection, after the effects of elevated Mitf have diminished.

The consequence of the elevation of Mitf protein levels in response to cAMP is that the tyrosinase, Tyrp-1, and Dct promoters are activated via the $\mathrm{M}$ box, and tyrosinase initiator E box (Bertolotto et al. 1996, 1998a,b). Thus unlike the CRE, where activation of transcription is a direct result of phosphorylation of the cAMP response element-binding protein CREB or related factors, the ability of an $\mathrm{M}$ box to respond to cAMP requires translation of Mitf following activation of the Mitf promoter. One of the kinases likely to be responsible for the cAMP-induced phosphorylation of CREB Ser133 is not the cAMP-dependent protein kinase, PKA, but rather the MAP kinase-activated kinase p90 Rsk (Böhm et al. 1995; Z. Abdel-Malek, pers. comm.). Results from both neuronal cells and mouse melanocyte and melanoma cell lines indicate that elevation of cAMP levels results in activation of the MAP kinase pathway (Fig. 3) (Engalaro et al. 1995; Erhardt et al. 1995; Vossler et al. 1997). Indeed, recent evidence suggests that mouse melanocytes may make use of a novel Ras GTP exchange factor that directly responds to cAMP (Buscà et al. 2000). Thus, upregulation of cAMP levels by melanocyte-stimulating hormone (MSH) signaling for example, would result in activation of Ras and the downstream MAP kinase cascade. The identity of the putative exchange factor is currently under investigation. However, the cross-talk between cAMP signaling and the MAP kinase pathway, though firmly established in mouse cells in culture, has yet to be observed in human melanocytes (Z. AbdelMalek, pers. comm.). It is possible, though probably unlikely, that this may represent an important species difference, or perhaps may reflect a signaling network that operates normally only at certain times during human development.

The ability of Mitf levels to be increased in response to elevated cAMP levels would suggest that in principle Mitf expression should be regulated by the melanocortin-1 receptor (Mc1r; $\mathrm{MSH}$ receptor) (Mountjoy et al. 1992) that acts via a heterotrimeric G-protein complex to regulate adenylate cyclase and intracellular cAMP in response to ligand binding (for review of Mclr function, see Jordan and Jackson 1998). Consistent with this, $\alpha-\mathrm{MSH}$ can indeed induce Mitf expression and this induction can be inhibited by the agouti signal protein, an antagonist at the Mclr (Aberdam et al. 1998; Price et al. 1998b). However, given the burst-attenuation kinetics of CREB phosphorylation (Hagiwara et al. 1992; Wadzinski et al. 1993/ and consequently, the transient nature of Mitf expression in response to cAMP, even a long-term activation of the Mclr may result in only a very transient increase in Mitf protein. Moreover, as the dephosphorylation of CREB may be followed by a refractory period of 3-5 days during which cells become transcriptionally unresponsive to stimulation by cAMP (Armstrong et al. 1995), stimulation of cells with agents such 


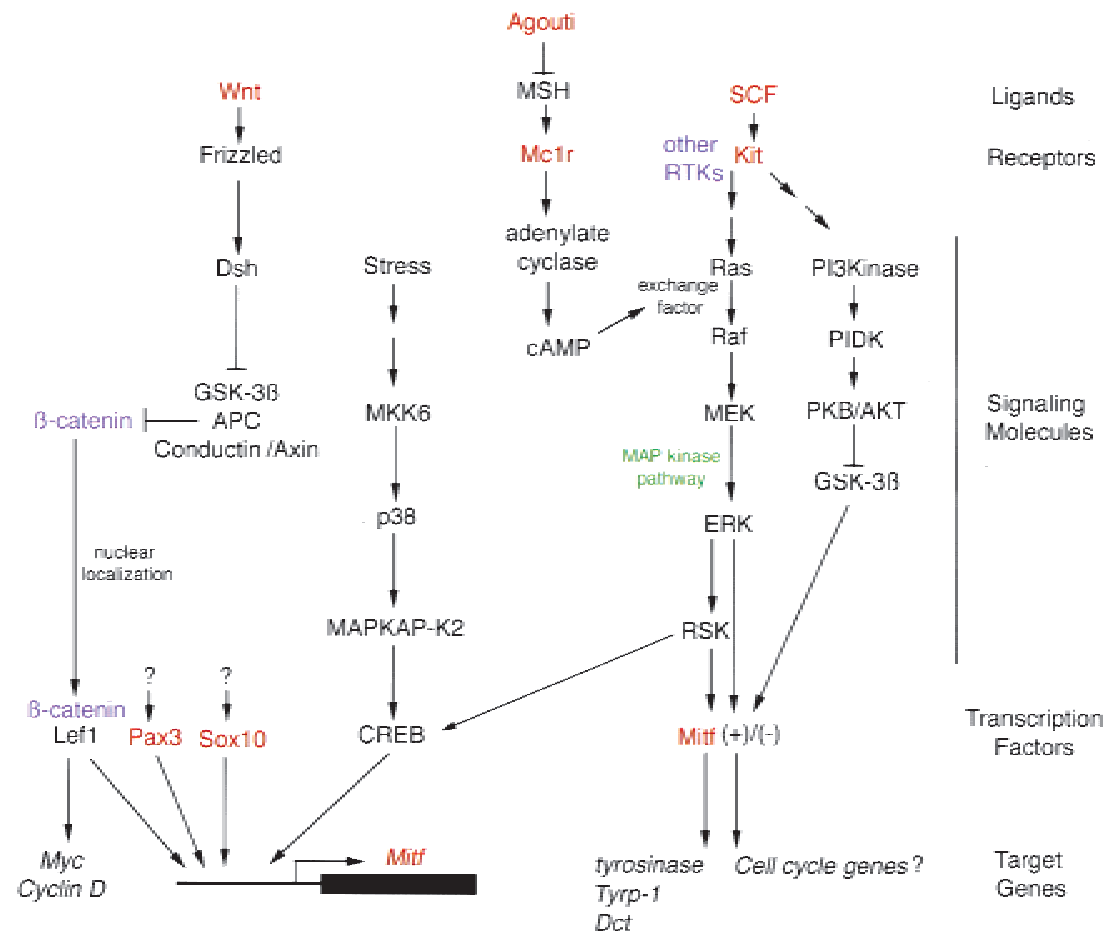

Figure 3. A simplified schematic showing features of key regulatory pathways in the melanocyte lineage. Signaling which would influence the activity of the melanosome by posttranslational modifications are not shown. Those signaling molecules or transcription factors that have been implicated genetically in melanocyte development are shown in red, while molecules implicated in melanoma are indicated in blue. In melanoma cell lines two key developmental pathways are known to be deregulated. First, melanomas are known to express a number of RTKs that are not normally expressed in melanocytes, but which may be expressed in melanoblasts. The impact of any individual RTKs on the development or transformation of the melanocyte lineage is likely to reflect the amplitude, duration, and kinetics of the downstream signals generated on ligand binding. Note that signaling by Kit and other RTKs will activate the MAP kinase signaling pathway and has been reported both to increase the transcriptional activity of Mitf as well as down-regulate Mitf protein levels. Second, Wnt signaling is bypassed in many melanoma cell lines owing to mutations in $\beta$-catenin which result in its stabilization. Although deregulation of Wnt- and RTK-mediated signaling will affect a range of target genes, both pathways impact on Mitf expression or Mitf levels. Note also that while GSK-3 $\beta$ is regulated by both RTK signaling and the Wnt signaling pathway, it is likely that each pathway regulates a different pool of GSK-3 $\beta$.

as MSH that result in increased cAMP levels might only result in a short pulse of Mitf expression which is refractive to subsequent stimuli. Any sustained increase of pigmentation in response to MSH might arise either from regulation of other transcription factors or posttranslational effects on proteins in the melanosome. Intriguingly, the $M C 1 R$ promoter may be regulated by Mitf (Adachi et al. 2000), at least in mast cells, raising the possibility that Mitf and Mc1R participate in a feedback loop.

The ability of the Mitf promoter to be regulated by CREB in response to cAMP also suggests that Mitf transcription will be responsive to other signals that are known to increase the phosphorylation of CREB on Ser133. For example, in some cell types the EGF and NGF receptors can induce phosphorylation of CREB via either the MAP kinase-dependent Rsk family, or the stress-responsive p38-dependent kinase MAPKAP-K2 (mitogen-activated protein kinase-activated protein-2) (Xing et al. 1996, 1998) which can mediate activation of CREB in response to stress and UV irradiation (Tan et al. 1996; Iordanov et al. 1997; Xing et al. 1998). Perhaps more significantly, as discussed above, MAP kinase/ Rsk-mediated phosphorylation of CREB Ser133 also occurs in response to both Ednrb and Kit-mediated signaling (Böhm et al. 1995). Thus it is possible that one role of these receptors may be to induce Mitf expression through the CRE. It remains to be seen whether the response of CREB to these stimuli translates into a transient or more prolonged activation of Mitf expression.
Regulation of Mitf expression by the Wnt/ $\beta$-catenin signaling pathway The Wnt-signaling pathway (Fig. 3) has been implicated in a variety of developmental decisions (for a review of Wnt signaling, see Cadigan and Nusse 1997), and at least two lines of evidence implicate Wnt signaling in the development of the melanocyte lineage: First, in the zebrafish and in the mouse, overexpression of components of the Wnt-signaling pathway promotes pigment cell formation at the expense of neurons and glia (Dorsky et al. 1998; B. Pavan, pers. comm.); and second, although most mice lacking both the Wnt-1 and Wnt-3a signaling molecules die in utero prior to E18.5, virtually all Dct-positive cells migrating from the neural crest are absent from E11.5 embryos, consistent with a failure of the developmental pathway leading to the production of Dct-expressing melanocyte precursor cells (Ikeya et al. 1997).

The components of the Wnt signaling pathway are highly conserved between species as diverse as Drosophila, Caenorhabiditus elegans, Xenopus, and man. The presence of a Wnt ligand activates the receptor for Wnt, the seven transmembrane domain protein Frizzled, which in turn leads to activation of Dishevelled, and subsequently to the inhibition of GSK-3 $\beta$. Current models suggest that the action of GSK-3 $\beta$ results in phosphorylation of $\beta$-catenin leading to its destabilization and degradation (Cadigan and Nusse 1997) and as a consequence, the presence of a Wnt signal increases the level of $\beta$-catenin in the cell. Control of $\beta$-catenin degradation is also influenced by components of a complex 
containing the product of the adenomatous polyposis coli gene $A P C$, which is a good substrate for GSK-3 $\beta$ in vitro and which can form a complex with GSK-3 $\beta$ and $\beta$-catenin, together with the axin homolog conductin (Rubinfeld et al. 1993, 1996; Behrens et al. 1998). Indeed, phosphorylation of APC by GSK-3 $\beta$ stimulates its ability to bind $\beta$-catenin and overexpression of APC following transfection substantially reduces $\beta$-catenin levels (Munemitsu et al. 1995). Similarly, overexpression of conductin also results in degradation of $\beta$-catenin and it has been suggested that conductin acts downstream from APC in directing the destabilization of $\beta$-catenin (Behrens et al. 1998).

One consequence of the stabilization of $\beta$-catenin, either as a result of Wnt signaling or as a consequence of the mutations found in melanomas, is that $\beta$-catenin is translocated to the nucleus where it forms a complex with members of the Lef/Tcf family of transcription factors (Behrens et al. 1996; Huber et al. 1996; Molenaar et al. 1996). Like Sox10, these proteins are related to the sex-determining factor SRY and are known as architectural transcription factors owing to their ability to bend DNA dramatically (Giese et al. 1992). The constitution of a Lef/Tcf- $\beta$-catenin complex following the stabilization of $\beta$-catenin and its nuclear localization results in the formation of a potent transcription activator. However, in the absence of interaction with $\beta$-catenin, the evidence available suggests that on some promoters Lef/ Tcf factors may act negatively (Brannon et al. 1997), for example by interacting with members of the Groucho family of transcriptional corepressors (Cavallo et al. 1998; Levanon et al. 1998; Roose et al. 1998). Repression mediated by Lef1/Tcf-Groucho complex is alleviated by the displacement of Groucho by $\beta$-catenin resulting in gene activation.

One model arising from these observations would be that Wnt signaling would be required in the neural crest to derepress Lef1/Tcf target genes that are involved in the initiation or maintenance of commitment to the melanocyte lineage. Significantly, results from Dorsky et al. (2000) revealed that the promoter for the nacre gene, encoding a zebrafish Mitf contained binding sites for functional Lef1/Tcf factors that are required for expression of nacre in the developing embryo. Nacre expression was also down-regulated in transfection assays by expression of dominant-negative Tcf3. Together the results implicate Wnt signaling in the control of nacre/Mitf expression in vivo and explain why ectopic expression of Wnt in the neural crest yields an increased number of pigment cells. The ability of the Mitf promoter to respond to Wnt3a signals via $\beta$-catenin is conserved between species as a functional Lef1 binding site is present in the human and mouse Mitf promoters (Fig. 2A) (Takeda et al. 2000b). Thus, the loss of melanoblasts in Wnt1/Wnt3 deficient mice may reflect the consequent failure of the Mitf promoter to be de-repressed in the neural crest.

The initiation of Mitf expression and the genetic hierarchy Although much is known about the factors regulating the proximal Mitf promoter, perhaps one of the most significant outstanding questions concerns the initiation of Mitf expression. The Mitf promoter appears to be regulated by Sox10, Pax3, and the Wnt/ $\beta$-catenin signaling pathway acting via Lef 1 , in addition to its regulation through the cAMP response element. Because all these factors and pathways operate widely in the neural crest, why is Mitf expression restricted to a relatively small number of neural crest cells? Although other explanations are possible, perhaps the most likely scenario is that the stable initiation of Mitf expression is a stochastic event which occurs only after the action of a combination of transcription factors exceeds a critical threshold required to overcome the nucleosomal barrier to transcription initiation. Once Mitf expression is initiated, the maintenance of Mitf expression ensures a continued commitment to the melanocyte lineage. The notion that stochastic events can play a fundamental role in commitment or differentiation has been described previously (Levenson and Housman 1981) and relates to the stabilization concept described by Bennett using single cell assays for B16 melanoma cell differentiation (Bennett 1983). It is also important to remember that while Pax3 and Lef1 have been described as positive regulators of Mitf expression, Lef1 in the absence of a Wnt signal can repress transcription in association with Groucho-like factors. Similarly, under some circumstances Pax3 can repress transcription, perhaps through its interaction with HIRA (Magnaghi et al. 1998), a mammalian homolog of a yeast transcriptional corepressor, and with the transcriptional repressor hDaxx which can suppress the ability of Pax3 to activate transcription (Hollenbach et al. 1999). It is possible, therefore, that in many cells in the neural crest, negative regulation operates to repress Mitf expression while only a few cells find themselves in an environment in which repression is alleviated. Thus, the expression of proteins such as Sox10, Pax3, and Lef1 may be insufficient to activate transcription without the impact of signal transduction pathways that would themselves be controlled by environmental cues. The nature of any potential regulation of the Sox10, Pax3, and Lef1 transcription factors is currently poorly understood.

One concept to emerge from the analysis of the Mitf promoter is that the ability of individual transcription factors to activate the Mitf promoter may reflect a genetic hierarchy. It is curious, for example, that while the CRE in the Mitf promoter is fully functional in melanocytes and will operate upstream of a heterologous promoter in cells unrelated to the melanocyte lineage, the CRE is inactive in other cell types in the context of the Mitf promoter (Bertolotto et al. 1998a; Price et al. 1998b). One possible explanation for this is that nucleosomes present across the Mitf promoter act as a barrier to factors such as CREB which bind the CRE, but do not impede access by other factors that regulate Mitf expression. It is already known that CREB and related factors cannot access their binding sites if incorporated into nucleosomal DNA (Schild-Poulter et al. 1996). Thus, during development the CRE may only be responsive to cAMP if the promoter has been primed already by other 
regulatory factors such as $\operatorname{Pax} 3$ or Sox10, thereby providing a mechanism to prevent inappropriate spatial or temporal expression from the Mitf promoter via promiscuous activation of the CRE.

\section{Downstream targets for Mitf}

Tyrosinase, Tyrp-1, and Dct Of the two melanocytespecific promoters, tyrosinase and Tyrp-1, that have been analyzed in detail, the tyrosinase promoter has received most attention and its regulation has been the subject of a review (Ferguson and Kidson 1997). Early experiments established that the proximal tyrosinase promoter extending to -270 with respect to the transcription start site was sufficient for correct temporal and pigment cell-specific expression in transgenic mice (Beermann et al. 1992). However, expression levels were low and were dependent on the position of the integrated transgene, indicating that additional sequences were required to recapitulate full expression. Full and positionindependent tyrosinase expression could be achieved by the inclusion in the expression vectors of an enhancer normally located around 12-kb upstream from the proximal promoter (Ganss et al. 1994a; Porter and Meyer 1994). Although this enhancer clearly plays a significant role in vivo, little is known about the transcription factors that bind this element or whether it is subject to regulation. In contrast, the proximal promoter has been characterized extensively (Bentley et al. 1994; Ganss et al. 1994b) with three key elements identified to date which are highly conserved between species. These are an Sp1 transcription factor binding site at -40 , an E box element (CATGTG) located at -12 that represents a binding site for members of the bHLH or bHLH-LZ families of transcription factors, and the 11-bp M box at -104 which is also conserved in the Tyrp-1, and Dct genes (Jackson et al. 1991; Lowings et al. 1992; Bentley et al. 1994). The M box also contains a CATGTG E box motif at its core, and because of its high degree of conservation between both species and promoters, it was immediately considered as a candidate for binding a melanocyte-specific bHLH or bHLH-LZ factor.

With the isolation of the gene encoding Mitf, it became apparent that both the $\mathrm{M}$ box and the tyrosinase initiator E box element were able to bind Mitf and could be activated by Mitf in transient transfection assays (Bentley et al. 1994; Ganss et al. 1994b; Hemesath et al. 1994; Yasumoto et al. 1994; Yokoyama et al. 1994; Yavuzer et al. 1995). In addition, Mitf was able to recognize and activate transcription from a third CATGTG E box motif, the tyrosinase distal element (TDE) located some 1.2-kb upstream from the tyrosinase promoter (Shibata et al. 1992; Yasumoto et al. 1994) and via the M boxrelated sequences in the Dct (Bertolotto et al. 1998b) and Qnr71 promoters (Turque et al. 1996). However, while these E box motifs may be targeted by Mitf, all cells including melanocytes contain multiple $\mathrm{E}$ box binding factors and, consistent with this, the $M$ box will activate transcription in nonmelanocytes if fused to a heterolo- gous promoter (Lowings et al. 1992). A simple promoter such as that of the tyrosinase gene, comprising two E box motifs and an SP1 site, should in principle be active in all cell types, yet it is active specifically in melanocytes. How the tyrosinase promoter achieves its cell-type specificity remains an unsolved puzzle. One possibility is that cell-type specificity is somehow built into the proximal promoter, for example through the targeting of sequences around the TATA box melanocyte-specific components of the basal transcription machinery, similar to that described for B-cells (Dikstein et al. 1996). This idea is supported by mutational analysis of the Tyrp-1 promoter which revealed that at least some degree of tissue-specificity was conferred by the TATA region (Yavuzer and Goding 1994). In addition, it is also possible that specificity is dictated by the spatial arrangement of the elements within the promoter. It is remarkable that the distance between the tyrosinase initiator $\mathrm{E}$ box and the $\mathrm{M}$ box is conserved absolutely in evolution, from turtle to man and at around $90 \mathrm{bp}$ is close to one turn of a DNA around a nucleosome. Whether the positioning of a nucleosome across the tyrosinase promoter facilitates the interaction between factors acting at the promoter by the juxtaposition of the two E box motifs is not known.

Mitf DNA-binding specificity The ability of Mitf to regulate transcription through the $\mathrm{M}$ box and other $\mathrm{E}$ box elements present in the melanocyte-specific promoters raises a fundamental question of specificity. If multiple members of the bHLH-LZ family such as Mitf, Myc, and USF (uppstream stimulatory factor) are simultaneously present in a given cell type, what mechanisms determine which factor will be active on any specific target element? Which factor may operate in vivo at any given moment will be dictated by several factors: the relative abundance of each factor; cooperative interactions with other factors may restrict the repertoire of factors able to function on a particular promoter; signal transduction pathways may differentially regulate the DNA-binding activity or activation capacity of individual family members; and differences in sequences flanking the shared core binding motif may lead to different affinities for any particular target element.

Regulation of the melanocyte-specific promoters also raises two further important questions concerning the specificity of an Mitf-mediated transcriptional response. First, because Mitf is essential to the development of the melanocyte lineage, it must regulate genes other than those involved in melanogenesis because the genes involved in melanogenesis are not essential for melanocyte survival. The nature of such additional Mitf target genes is a matter of much speculation but is likely to include genes involved in regulation of the cell cycle or of apoptosis that might well not be melanocyte-specific. One clue as to the identity of these as yet unidentified target genes is that their promoters will be recognized by Mitf and consequently will contain E box elements. This brings us to the second question: E box elements are found in many promoters, many of which are unlikely to 
be recognized by Mitf in vivo. Some mechanism must therefore exist to restrict the ability of Mitf to activate transcription to a subset of such promoters. The observation that Mitf binds a restricted subset of $\mathrm{E}$ box elements (Aksan and Goding 1998) may be useful. In vitro studies have determined that Mitf can bind both CATGTG and CACGTG E box elements (Hemesath et al. 1994). However, the ability of Mitf to recognize the CATGTG class of E box is restricted by an absolute requirement for an additional $\mathrm{T}$ residue $5^{\prime}$ to either half site (Aksan and Goding 1998). In other words, Mitf will bind either TCATGTGN, NCATGTGA, or TCATGTGA. The significance of this observation is highlighted by the fact that all those elements through which Mitf is known to act, the evolutionarily conserved $M$ box in the tyrosinase, Tyrp-1, Dct, and Qnr71 promoters as well as the tyrosinase TDE and initiator E box, all conform to this rule. In contrast, a CATGTG E box in the promoter for the $P$ gene, also involved in pigmentation, does not possess the correct flanking sequence and consequently fails to bind Mitf in vitro (Aksan and Goding 1998).

The presence of full consensus Mitf binding sites has been observed recently in the promoter for the gene encoding the Mclr which appears to be regulated by Mitf in mast cells (Adachi et al. 2000), and in the promoter for the gene encoding the T-box transcription factor Tbx2 (Carreira et al. 2000) which is expressed in melanoblasts and melanocyte cell lines but not in melanoblast precursor cells (Carreira et al. 1998). However, while the promoters for these genes can bind Mitf in vitro and be regulated by Mitf in transfection assays, it remains to be seen whether they represent targets for endogenous Mitf in cells or during development.

While the requirement for a $\mathrm{T}$ residue flanking a CATGTG motif dictates that Mitf will only be able to recognize a specific subset of CATGTG E boxes, binding to CACGTG E boxes appears to be indiscriminate in vitro. Why then, do the melanocyte-specific promoters contain CATGTG E boxes exclusively? First, by using the CATGTG motif, the melanocyte-specific promoters will avoid the necessity for Mitf to compete for binding with bHLH-LZ factors able to target the CACGTG type E box; and second, the absence of CACGTG elements will prevent regulation by factors able to target this type of $\mathrm{E}$ box uniquely or that have a higher affinity for this motif than Mitf. Occupancy of any E box in vivo will be dynamic. In the case of the M box, it is likely that there is competition for recognition of this sequence between Mitf and other bHLH-LZ transcription factors such as USF which is known to recognize Mitf-target sites (Aksan and Goding 1998). In response to increased cAMP levels, the concentration of Mitf in the cell is elevated (Bertolotto et al. 1998c), and as a consequence the ability of Mitf to compete with USF will be increased. On the other hand, the ability of USF to activate transcription also appears to be regulated (Galibert et al. 1997), and a combination of a lack of cAMP signaling together with increased activity of USF in response to an appropriate signal may mean that at other times the $M$ box is regulated by USF.

\section{Regulation of Mitf function}

Given the importance of Mitf in melanocyte development, it is not surprising that Mitf function is mediated both by protein-protein interactions and regulation by specific signal transduction pathways. These are summarized in Figure 2B and described in more detail below.

The Mitf activation domain and interaction with CBP/ p300 The ability of Mitf to activate transcription is mediated primarily through an amino-terminal transcription activation (AD1, Fig. 2B) domain lying between residues 114 and 135 within exon 4 (Sato et al. 1997). This region is deleted in the Mitf ${ }^{m i-\times 39}$ mutant (Hallsson et al. 2000) yielding a phenotype consistent with the mutant form of Mitf acting as a dominant-negative protein. The activation domain is predicted to adopt an amphipathic $\alpha$-helical conformation, is highly conserved between different members of the Mitf subfamily of bHLH-LZ transcription factors, and bears a striking similarity to a region of the adenovirus E1A protein which mediates the interaction between E1A and the cellular transcriptional cofactors p300 and CBP (Sato et al. 1997). CBP and p300 are highly related proteins that act as cofactors for many transcription factors, including the nuclear hormone receptors, Myb and CREB (for review, see Janknecht and Hunter 1996). Within CBP and p300 discrete domains have been defined that mediate interaction with different transcription factors, as well as a transcription activation domain and a region that possesses histone acetyl transferase activity that can acetylate both nucleosomal histones and other factors. Interaction between Mitf and CBP or p300 was demonstrated by coimmunoprecipitation (Sato et al. 1997; Price et al. 1998a) and, as expected from the amino acid homology, the Mitf activation domain was found to interact with the same region of CBP which interacts with E1A (Sato et al. 1997). This is distinct from those that mediate interaction with the nuclear hormone receptors, or with Myb and CREB. The interaction between Mitf and CBP/p300 is likely to be important for melanocyte development because E1A can abolish the ability of the $\mathrm{M}$ box to direct transcription activation (Yavuzer et al. 1995); E1A acting to partition $\mathrm{CBP} / \mathrm{p} 300$ from Mitf and thereby reduce its ability to activate transcription. Consistent with this, repression of $\mathrm{M}$ box function is largely abolished using E1A mutants which can no longer bind CBP/p300 (Yavuzer et al. 1995). Moreover, expression of E1A in the pigmented mouse melanocyte cell line melan-a results in dedifferentiation of the cells and loss of melanogenic markers (Yavuzer et al. 1995). However, it is not possible to distinguish whether this effect depends on the ability of E1A to partition CBP/p300 from Mitf, resulting in a failure to activate downstream Mitf target genes, or CBP/ p300 from CREB, which acts at the Mitf promoter, leading to loss of Mitf expression.

Although the amino-terminal transcription activation domain has been well characterized, there is some evidence to suggest that a second activation domain $/ \mathrm{ad} 2$, Fig. 2B) may reside within the Mitf carboxy-terminal region. A block of amino acids (LEDILMDD) with a high 
degree of similarity to the amino-terminal activation domain is highly conserved between Mitf proteins derived from organisms as diverse as man and ascidians $(\mathrm{H}$. Yamamoto, pers. comm.). This region is also conserved and can act as an activation domain in TFE3 (Artandi et al. 1995), and the carboxy-terminal region of Mitf encompassing these conserved residues will activate transcription weakly in Saccharomyces cerevisiae. It seems likely therefore that this conserved motif may function as an activation domain in mammalian cells, but perhaps only when Mitf receives an appropriate signal.

Signaling by Kit and regulation of Mitf The Kit RTK (receptor tyrosine kinase) plays a critical role in melanocyte development; mutations affecting the function of the Kit gene, or the Mgf gene encoding the ligand for Kit (Kit ligand, Stem cell factor, Mast cell growth factor) (Huang et al. 1990; Williams et al. 1990; Zsebo et al. 1990), result in the partial or complete loss of neural crest-derived melanocytes depending on the severity of the allele (Fig. 1H) (for reviews, see Jackson 1994; Lev et al. 1994). Similarly, injection intradermally into pregnant mice of monoclonal anti-Kit antibody with the capacity to block receptor signaling revealed a specific requirement for Kit signaling in melanocyte development at around E14.5 and postnatally (Nishikawa et al. 1991). Results obtained from many studies using complementary approaches have generated a picture in which the survival and proliferation of neural crest-derived melanoblasts appears to be critically dependent on Kit signaling. For example, in the study by Mackenzie (1997) 10.5day old homozygous $\mathrm{Kit}^{W-v}$ mutant embryos have fewer melanoblasts than a wild-type animal, though their spatial distribution is similar to wild type, but by E11.5 the numbers are reduced and melanoblasts are absent by E12.5. In a heterozygous $\mathrm{Kit}^{W-\mathrm{V}}$ animal, melanoblast numbers do not increase at the same rate as in wild-type mice. Several conclusions can be drawn from this and other similar studies. First, Kit signaling is not absolutely essential for the initial generation of cells expressing melanoblast markers; second, Kit is critically required for melanoblast survival; and third, Kit signaling is necessary for the increase in melanoblast numbers seen during the development of a wild-type animal.

One reason why the lack of fully functional Kit results in the failure of the melanoblasts to persist and accumulate is that Kit delivers an antiapoptotic signal. In the zebrafish, the ortholog of Kit, Sparse, is required both for migration and survival of embryonic melanocytes, with melanocytes undergoing apoptosis in the absence of Kit signaling (Parichy et al. 1999). On interaction with its ligand, Kit, like other RTKs, undergoes dimerization, its tyrosine kinase activity is induced and the activation of multiple signaling pathways including both the PI(3) kinase $[\mathrm{PI}(3) \mathrm{K}]$ and MAP kinase cascades (Fig. 3) results (for review of Kit signaling, see Lev et al. 1994).

Recent advances have shed light on how activation of $\mathrm{PI}(3) \mathrm{K}$, which leads to rapid elevation of the levels of phosphatidyl inositol 3,4,5 triphosphate in vivo, can deliver a powerful anti-apoptotic signal via activation of the kinases PDK1 (Alessi et al. 1997a,b; Stokoe et al. 1997) and Akt (protein kinase B) (Fig. 3). However, although this pathway is likely to operate in the melanocyte lineage, no specific examples of Akt signaling to downstream molecules in melanocyte development are available. More importantly, the introduction of a specific Y719F mutation into the genomic Kit locus to disrupt $\mathrm{PI}(3) \mathrm{K}$ binding to Kit, decreased Kit signaling to Akt by $>90 \%$ and resulted in male infertility, yet apparently failed to affect the melanocyte lineage (Blume-Jensen et al. 2000; Kissel et al. 2000).

In addition to activation of $\mathrm{PI}(3) \mathrm{K}$, Kit can also activate the MAP kinase pathway, a kinase cascade (Fig. 3) in which Ras-dependent activation of Raf results in the phosphorylation of MEK (MAP kinase-kinase), which then mediates the phosphorylation and activation of MAP kinase (ERK), and finally p90 Rsk family members are activated by phosphorylation by ERK. Following phosphorylation, MAP kinase undergoes dimerization and $\sim 50 \%$ of the protein translocates to the nucleus.

The similarity between the phenotypes of kit and mitf mutant mice, namely a loss of neural crest-derived melanocytes, suggested a functional relationship between the two proteins. The nature of that relationship was revealed partially with the observation that Mitf is phosphorylated on Ser73 by the MAP kinase ERK2 (Hemesath et al. 1998; Fig. 2B). Because ERK2 lies in the MAP kinase pathway downstream from Kit and other RTKs (Fig. 3), the ability of Mitf to be phosphorylated by ERK2 in response to signaling by Kit nicely linked the phenotypes of mice defective for Kit and Mitf. However, whereas the evidence that Mitf is phosphorylated on Ser73 by ERK2 is well established, some controversy has surrounded the precise role of phosphorylation in the regulation of Mitf function. On the one hand, Hemesath et al. (1998) were able to show that the ability of Mitf to activate an M-box reporter was enhanced in response to MAP kinase signaling and consistent with this, Price et al. (1998a) demonstrated that the transcription cofactor p300 preferentially coimmunoprecipitated with phospho-Mitf. In contrast, no significant preference for phospho-Mitf was seen in coimmunoprecipitations with the p300-related protein CBP (Sato et al. 1997). Moreover, recent evidence (Wu et al. 2000; Xu et al. 2000) indicates that Mitf protein stability is regulated negatively by phosphorylation by the MAP kinase pathway. Xu et al. (2000) were able to identify the ubiquitin/SUMO-conjugating enzyme UBC9 as a Mitf-interacting protein in a yeast two-hybrid screen. Overexpression of UBC9 in transfected cells promoted proteosome-mediated degradation of phosphorylated Mitf that was inhibited by mutation of the MAP kinase phosphorylation site Ser73 to alanine. The conclusion from this work was that phosphorylation of Mitf by MAP kinase promotes ubiquitination on K201 and subsequent targeting to the proteosome for degradation. The interpretation of the experiments on the regulation of Mitf by the MAP kinase pathway was further complicated by the observation that Ser409 at the carboxy terminus of Mitf is likely to be a target in vivo for the MAP kinase-activated kinase 
p90 Rsk (Wu et al. 2000). In contrast to the results of Xu et al. (2000), Wu et al. (2000) have reported that Mitf stability is negatively regulated by either MAP kinasemediated phosphorylation of Mitf on Ser73 or by phosphorylation by Rsk on Ser409, with only a double-alanine substitution at residues 73 and 409 being sufficient to stabilize the protein in the presence of a Kit signal. Although other possibilities exist, the differences in the results obtained may reflect the fact that the different cell lines used in the two studies are likely to be characterized by different levels of constitutive MAP kinase signaling and differences in the amplitude and duration of signaling events. If so, it serves to highlight the care that must be taken in using cell lines to study regulation of Mitf by signal transduction pathways that may be differentially active between species or from one cell line to another. Notwithstanding these caveats, one firm conclusion that can be drawn is that regulation of Mitf protein stability is a key feature of MAP kinase signaling to Mitf. Precisely when Mitf is phosphorylated during development is unknown however, and must await the development of reagents designed to detect specifically phosphorylated and nonphosphorylated forms of Mitf.

So, does Kit signaling and the MAP kinase pathway regulate Mitf positively or negatively? While it might be expected that the absence of melanocytes arising from loss of Kit signaling results in part from loss of Mitf function if MAP kinase regulated Mitf in a positive fashion, it might equally be argued that if Mitf were overexpressed it would result in cell death, as has been seen in mast cells (Tsujimura et al. 1997). This would be similar to the observed apoptosis in fibroblasts grown in low serum in response to overexpression of Myc (Evan et al. 1992) which can activate transcription from Mitf targets (Turque et al. 1996; Aksan and Goding 1998). If this were the case, then the role of the MAP kinase cascade would be to prevent Mitf from becoming too active, which would be consistent with the data indicating that the MAP kinase pathway targets Mitf for degradation (Wu et al. 2000; Xu et al. 2000). It is not inconceivable that MAP kinase signaling may regulate Mitf both positively and negatively, depending on the kinetics, amplitude, and duration of the signal received, which may depend on the timing of RTK signaling. This in turn will depend on the nature of the receptors initiating the signal, as well as other as yet poorly understood factors such as whether the Kit ligand is soluble or cell bound. Clearly much more needs to be done before these key questions can be resolved.

Regulation of Mitf by glycogen synthase kinase$3 \beta$ The multiple mutations affecting Mitf function in the mouse and humans have provided an invaluable resource for the analysis of Mitf function. One mutation found in a human WS2 family that has proved informative affects Ser298 located immediately carboxy-terminal to the bHLH-LZ domain. This serine appears to be phosphorylated by GSK-3 $\beta$ in vitro and in vivo and phosphorylation at this site promotes Mitf DNA-binding (Takeda et al. 2000a). The GSK-3 $\beta$ kinase is regulated by at least two signal transduction pathways (Fig. 3). First, GSK-3 $\beta$ is inhibited by AKT (PKB) which lies downstream from PI $(3) \mathrm{K}$ and RTK-mediated signaling; second, GSK-3 $\beta$ is a component of the WNT-signaling pathway lying upstream from $\beta$-catenin. Although in principle RTK signaling should regulate $\beta$-catenin stability, there is no evidence that this occurs and it seems likely that different pools of GSK-3 $\beta$ may be present in distinct compartments within the cell. Whether the GSK-3 $\beta$ that regulates Mitf-DNA binding is regulated by Wnt signaling, which can also stimulate Mitf expression via activation of the Mitf promoter (see above), or whether Mitf phosphorylation by GSK- $3 \beta$ it is controlled by AKT has yet to be determined.

\section{Mitf and malignant melanoma}

All cancers including malignant melanoma are characterized by the perturbation of the controls operating on the cell cycle. As the mechanisms governing the cell cycle are conserved between different cell types, it should come as no surprise that lessons learned from the analysis of cell cycle controls are relevant to our understanding of melanoma. In particular, malignant melanoma is frequently associated with mutations inactivating the INK4a/ARF locus that encodes the p16 and p19 cyclin dependent kinases inhibitors (cdkis) (for review, see Chin et al. 1998). Loss of functional cdkis would lead to hyper-phosphorylation of p105 Rb and consequently an inefficient brake on the cell cycle.

Perhaps more interesting are the features of melanoma that reflect a deregulation of the developmental process operating in the genesis of the melanocyte lineage. Thus, in addition to mutations in INK4a/ARF, two key developmental pathways are known to be deregulated in melanoma cell lines.

First, melanomas express a number of RTKs that are not normally expressed in melanocytes (for review, see Chin et al. 1998), but which may be expressed in melanoblasts. The output from these RTKs is likely to be different from those RTKs such as Kit which are expressed in normal melanocytes in terms of amplitude, duration, and kinetics of downstream signal transduction pathways. The significance of RTK signaling in the genesis of melanoma is highlighted by the fact that the genetic inheritance of melanoma in the sword tail fish Xiphophorus correlates with expression of the Xmrk RTK (Wittbrodt et al. 1989). Because signaling by RTKs regulates the stability and function of Mitf, the deregulation of RTK signaling in melanomas will lead to inappropriate regulation of Mitf in addition to having a more general impact on gene regulation.

Second, Wnt signaling is bypassed in $\leq 30 \%$ of melanoma cell lines (Rubinfeld et al. 1997) which appear to have mutations that result in the stabilization of $\beta$-catenin either as a consequence of unusual mRNA splicing or because of specific mutations in the potential phospho-acceptor sites located in the amino-terminal region. Increased $\beta$-catenin levels have also been observed in melanomas expressing mutant forms of the APC tu- 
mor suppressor (Rubinfeld et al. 1997) and it is likely that mutations affecting $A X I N 1$, which have been implicated in hepatocellular carcinoma (Satoh et al. 2000), may also be found. The consequences of deregulation of the Wnt-signaling pathway will be the inappropriate expression of a wide range of genes controlled by $\beta$-catenininteracting factors which include the Lef1/Tcf family, members of the Sox family (Zorn et al. 1999), and Smad4 (Nishita et al. 2000). Genes regulated by $\beta$-catenin in association with LEF1/Tcf include Mitf, in addition to Myc (Tong-Chuan et al. 1998) and Cyclin D1 (Tetsu and McCormick 1999|. Thus, once again, deregulation of a developmental pathway in melanoma will result in deregulation of Mitf expression.

Together with the fact that Mitf is expressed in most if not all primary melanomas (King et al. 1999), these observations place deregulation of Mitf firmly in the spotlight and reinforce the notion that the origins of malignant melanoma may be inextricably linked to the developmental program underlying the genesis of the melanocyte lineage.

\section{Perspectives}

Although recent years have seen a revolution in our understanding of how transcription regulation and signal transduction pathways act to coordinate melanocyte development, several fundamental questions remain to be addressed.

First, Mitf lies at the heart of the development of the melanocyte lineage; most of the signaling molecules or transcription factors implicated genetically in melanocyte development affect either Mitf expression or its function. Yet several key questions concerning this protein remain outstanding. For example, is Mitf continuously required as suggested by the progressive age-related loss of melanocytes in the vitiligo-associated Mitf ${ }^{\text {Mi-vit }}$ mutant, or only necessary at one or more key stages of development? What genes are targeted by Mitf other than those required for pigmentation? When is Mitf phosphorylated by MAP kinase, Rsk, or GSK-3 $\beta$ during development and how are the regulatory mechanisms operating on Mitf that have been identified using cells in culture relevant to its function in development? What co-factors other than CBP/p300 are used by Mitf to execute its function in gene regulation? Moreover, while the elements controlling the proximal Mitf promoter in tissue culture have been examined, additional uncharacterized regulatory elements further upstream are required for correct spatial and temporal expression of Mitf in development. We also know nothing of how Sox10 or Pax3 are regulated or how the architecture of melanocyte-specific promoters may affect their regulation.

Second, despite the general preoccupation with Mitf, it is also evident that other bHLH-LZ transcription factors target Mitf binding sites. These include Myc and Max, USF, and various TFE3 family members. Although there is no genetic evidence implicating these factors in melanocyte development, this may reflect some degree of functional redundancy between these proteins, or more interestingly the possibility that their ability to regulate gene expression is tightly controlled and that they regulate transcription under specific circumstances, for example in response to stress signaling. If that is the case, when are these proteins active and what signal transduction pathways and co-factors facilitate their capacity to regulate gene expression?

Third, little attention has been paid to the kinetics or amplitude of the signals generated by the various receptors implicated in the melanocyte lineage. This is a particularly important point, because while any two RTKs may signal through the same pathways, whether they promote differentiation or proliferation may depend on whether, for example, they elicit a transient versus sustained activation of Ras/MAP kinase signaling (for review, see Marshall 1995). Given the different kinetics of the signals generated by different receptors, how does this impinge on the downstream targets such as Mitf? In the case of Kit, addition of soluble ligand to cultured cells results in a transient activation of the MAP kinase pathway which peaks at around 30' (Hemesath et al. 1998). However, Kit-ligand exists in two forms, soluble and cell bound which have been reported to play distinct roles in the survival and dispersal of neural crest-derived melanocyte precursors (Wehrle-Haller and Weston 1995). Given that the kinetics of activation of the MAP kinase pathway can dramatically affect the outcome of RTK signaling, it will be particularly important to determine whether cell-bound ligand delays the internalization of Kit and down-regulation of Kit signaling compared to the soluble ligand. If signaling were different, it might go some way to explaining the apparent differential requirements for the soluble and cell bound ligands. On a related note, how does the signaling by receptors such as EphA2, expressed in melanoblasts and melanoma but not in melanocytes, differ from those expressed in melanocytes?

Fourth, compelling evidence obtained from both targeted and natural mutations has implicated a failure in Edn3-mediated signaling via Ednrb as the molecular defect underlying the piebald lethal phenotype (Baynash et al. 1994; Hosoda et al. 1994; Puffenberger et al. 1994). A series of elegant experiments revealed that $E d n r b$ is required only transiently during the development of the melanocyte lineage, between E10 and E12.5 and is required for migration of melanoblasts (Shin et al. 1999). However, while Ednrb appears likely to signal via multiple pathways, no target genes have been clearly defined to date. It almost seems inevitable that before too long a link to the regulation of Mitf expression will be established which may in part account for the phenotype of the Ednrb mutants.

Finally, while mutations affecting genes involved in any step from the specification of the melanocyte lineage to melanocyte differentiation may result in a visible coat-color phenotype, some factors required for the development of the melanocyte lineage may be implicated more widely in development. Mutations affecting the function of at least some of these genes may result in an embryonic or neonatal lethal phenotype and such muta- 
tions will preclude the appearance of a coat-color phenotype. Nevertheless, it is anticipated that the availability of techniques to readily visualize melanoblasts during development coupled with the use of techniques for making site-specific or temporal mutations using conditional gene ablation technology will permit the number of genes implicated in the development of the melanocyte lineage to be extended considerably.

In summary, the isolation of the Mitf gene has provided a firm basis for our understanding of the controls operating on melanocyte development and has provided a focus for several genes genetically implicated in melanocyte development and malignant melanoma. The future promises the development of defined mouse models augmented by in vitro differentiation systems and the isolation of additional genes implicated in the genesis of the melanocyte lineage. Underpinned by the large genetic resource provided by the mouse and other species, particularly the zebrafish, the study of melanocyte development promises to provide novel insights into how the integration of gene expression and signal transduction pathways governs the development of a specific cell lineage.

\section{Acknowledgments}

I would like to thank those colleagues who communicated results before publication and to Nick Hastie for recommending this review. I am particularly indebted to Heinz Arnheiter, Dot Bennett, Eirikur Steingrímsson, and Robert Ballotti for constructive comments on the manuscript and Heinz Arnheiter, Bill Pavan, Tom Hornyak, and Hiroaki Yamamoto for generously contributing to Figure 1.

\section{References}

Aberdam, E., Bertolotto, C., Sviderskaya, E.V., de Thillot, V., Hemesath, T.J., Fisher, D.E., Bennett, D.C., Ortonne, J.-P., and Ballotti, R. 1998. Involvement of Microphthalmia in the inhibition of melanocyte lineage differentiation and of melanogenesis by agouti signal protein. J. Biol. Chem. 273: 19560-19565.

Adachi, S., Morii, E., Kim, D., Ogihara, H., Jippo, T., Ito, A., Lee, Y.M., and Kitamura, Y. 2000. Involvement of mi-transcription factor in expression of alphamelanocyte-stimulating hormone receptor in cultured mast cells of mice. J. Immunol. 164: 855-860.

Aksan, I. and Goding, C.R. 1998. Targeting the microphthalmia basic helix-loop-helix-leucine zipper transcription factor to a subset of E-Box elements in vitro and in vivo. Mol. Cell. Biol. 18: 6930-6938.

Alessi, D.R., Deak, M., Casamayor, A., Caudwell, F.B., Morrice, N., Norman, D.G., Gaffney, P., Reese, C.B., MacDougall, C.N., Harbison, D. et al. 1997a. 3-Phosphoinositide-dependent protein kinase-1 (PDK1): Structural and functional homology with the Drosophila DSTPK61 kinase. Curr. Biol. 7: 776-789.

Alessi, D.R., James, S.R., Downes, C.P., Holmes, A.B., Gaffney, P.R., Reese, C.B., and Cohen, P. 1997b. Characterization of a 3-phosphoinositide-dependent protein kinase which phosphorylates and activates protein kinase B alpha. Curr. Biol. 7: 261-269.
Armstrong, R., Wen, W., Meinkoth, J., Taylor, S., and Montminy, M. 1995. A refractory phase in cyclic-AMP-responsive transcription requires down-regulation of protein kinase A. Mol. Cell. Biol. 15: 1826-1832.

Artandi, S.E., Merrell, K., Avitahl, N., Wong, K.-K., and Calame, K. 1995. TFE 3 contains two activation domains, one acidic and the other proline-rich, that synergistically activate transcription. Nucleic Acids Res. 23: 3865-3871.

Baldwin, C.T., Lipsky, N.R., Hoth, C.F., Cohen, T., Mamuya, W., and Milunsky, A. 1994. Mutations in PAX3 associated with Waardenburg syndrome type I. Hum. Mutat. 3: 205211.

Baynash, A.G., Hosoda, K., Giaid, A., Richardson, J.A., Emoto, N., Hammer, R.E., and Yanagisawa, M. 1994. Interaction of endothelin-3 with endothelin-B receptor is essential for development of epidermal melanocytes and enteric neurons. Cell 79: 1277-1285.

Beermann, F., Schmid, E., and Schütz, G. 1992. Expression of the mouse tyrosinase gene during embryonic development: Recapitulation of the temporal regulation in transgenic mice. Proc. Nat1. Acad. Sci. 89: 2809-2813.

Behrens, J., von Kries, J.P., Kuhl, M., Bruhn, L., Wedlich, D., Grosschedl, R., and Birchmeier, W. 1996. Functional interaction of beta-catenin with the transcription factor LEF-1. Nature 382: 638-642.

Behrens, J., Jerchow, B.-A., Würtele, M., Grimm, J., Asbrand, C., Wirtz, R., Kühl, M., Wedlich, D., and Birchmeier, W. 1998. Functional interaction of an axin homolog conductin, with $\beta$-catenin, APC, and GSK3 $\beta$. Science 280: 596-599.

Bennett, D.C. 1983. Differentiation in mouse melanoma cells: Initial reversibility and an on-off stochastic model. Cell 34: 445-453.

Bentley, N.J., Eisen, T., and Goding, C.R. 1994. Melanocytespecific expression of the human tyrosinase promoter: Activation by the microphthalmia gene product and role of the initiator. Mol. Cell. Biol. 14: 7996-8006.

Bernex, F., De Sepulveda, P., Kress, C., Elbaz, C., Delouis, C., and Panthier, J.J. 1996. Spatial and temporal patterns of c-kitexpressing cells in WlacZ/+ and WlacZ/WlacZ mouse embryos. Development 122: 3023-3033.

Bertolotto, C., Ortonne, J.-P., and Ballotti, R. 1996. Regulation of tyrosinase gene expression by cAMP in B16 melanoma cells involves two CATGTG motifs surrounding the TATA box: Implication of the microphthalmia gene product. J. Cell. Sci. 134: 747-755.

Bertolotto, C., Abbe, P., Hemesath, T.J., Bile, K., Fisher, D.E., Ortonne, J.-P. and Ballotti, R. 1998a. Microphthalmia gene product as a signal transducer in cAMP-induced differentiation of melanocytes. J. Cell. Biol. 142: 827-835.

Bertolotto, C., Busca, R., Abbe, P., Bille, K., Aberdam, E., Ortonne, J.-P., and Ballotti, R. 1998b. Different cis-acting elements are involved in the regulation of TRP1 and TRP2 promoter activities by cyclin AMP: Pivotal role of M boxes (GTCATGTGCT) and of Microphthalmia. Mol. Cell. Biol. 18: 694-702.

Blume-Jensen, P., Jiang, G., Hyman, R., Lee, K.-F., O'Gorman, S., and Hunter, T. 2000. kit/stemcell factor receptor-induced activation of phosphatidylinositol $3^{\prime}$-kinase is essential for male fertility. Nat. Genet. 24: 157-162.

Böhm, M., Moellmann, G., Cheng, E., Alvarez-Franco, M., Wagner, S., Sassone Corsi, P., and Halaban, R. 1995. Identification of p90Rsk as the probable CRE-Ser133 kinase in melanocytes. Cell Growth Diff. 6: 291-302.

Boissy, R.E. and Lamoreux, L. 1995. In vivo and in vitro morphological analysis of melanocytes homozygous for the $m i^{s p}$ allele at the murine microphthalmia locus. Pigment Cell 
Res. 8: 294-301.

Brannon, M., Gomperts, M., Sumoy, L., Moon, R.T., and Kimelman, D. 1997. A $\beta$-catenin/XTcf-3 complex binds to the siamois promoter to regulate dorsal axis specification in Xenopus. Genes \& Dev. 11: 2359-2370.

Buscà, R., Abbe, P., Mantoux, F., Aberdam, E., Peyssonnaux, C., Eychène, A., Ortonne, J.P., and Ballotti, R. 2000. Ras mediates the cAMP-dependent activation of extracellular signal regulated kinases (ERKs) in melanocyte cells. EMBO $J$. 19: $2900-2910$

Cadigan, K.M. and Nusse, R. 1997. Wnt signaling: A common theme in animal development. Genes \& Dev. 11:32863305.

Carreira, S., Dexter, T.J., Yavuzer, U., Easty, D.J., and Goding, C.R. 1998. Brachyury-related transcription factor Tbx2 and repression of the melanocyte-specific TRP-1 promoter. Mol. Cell. Biol. 18: 5099-5108.

Carreira, S., Liu, B., and Goding, C.R. 2000. The gene encoding the T-box transcription factor Tbx2 is a target for the microphthalmia-associated transcription factor in melanocytes. J. Biol. Chem. (in press).

Cavallo, R.A., Cox, R.T., Moline, M.M., Roose, J., Polevoy, G.A., Clevers, H., Peifer, M., and Bejsovec, A. 1998. Drosophila Tcf and Groucho interact to repress Wingless signalling activity. Nature 395: 604-608.

Chin, L., Merlino, G., and Depinho, R.A. 1998. Malignant melanoma: Modern black plague and genetic black box. Genes \& Dev. 12: 3467-3481.

Dikstein, R., Zhou, S., and Tjian, R. 1996. Human TAFII 105 is a cell type-specific TFIID subunit related to hTAFII130. Cell 87: 137-146.

Dorsky, R.I., Moon, R.T., and Raible, D.W. 1998. Control of neural crest cell fate by the Wnt signalling pathway. Nature 396: 370-373.

Dorsky, R.I., Raible, D.W., and Moon, R.T. 2000. Direct regulation of nacre, a zebrafish MITF homolog required for pigment cell formation, by the Wnt pathway. Genes \& Dev. 14: 158-162.

Engalaro, W., Rezzonico, R., Durand-Clément, M., Lallemand, D., Ortonne, J.-P., and Ballotti, R. 1995. Mitogen-activated protein kinase pathway and AP1 are activated during CAMPinduced melanogenesis in B16 melanoma cells. J. Biol. Chem. 270: 24315-24320.

Erhardt, P., Trppmeir, J., Rapp, U.R., and Cooper, G.M. 1995. Differential regulation of Raf-1 and B-Raf and Ras-dependent activation of mitogen-activated protein kinase by cyclic AMP in PC12 cells. Mol. Cell. Biol. 15: 5524-5530.

Evan, G.I., Wyllie, A.H., Gilbert, C.S., Littlewood, T.D., Land, H., Brooks, M., Waters, C.M., Penn, L.Z., and Hancock, D.C. 1992. Induction of apoptosis in fibroblasts by c-myc protein. Cel1 69: 119-128.

Ferguson, C.A. and Kidson, S.H. 1997. The regulation of tyrosinase gene transcription. Pigment Cell. Res. 10: 127-138.

Fuse, N., Yasumoto, K.-I., Suzuki, H., Takahashi, K., and Shibahara, S. 1996. Identification of a melanocyte-type promoter of the microphthalmia-associated transcription factor gene. Biochem. Biophys. Res. Com. 219: 702-707.

Fuse, N., Yasumoto, K., Takeda, K., Amae, S., Yoshizawa, M., Udono, T., Takahashi, K., Tamai, M., Tomita, Y., Tachibana, M. et al. 1999. Molecular cloning of cDNA encoding a novel microphthalmia-associated transcription factor isoform with a distinct amino-terminus. I. Biochem. 126: 10431051.

Galibert, M.-D., Boucontet, L., Goding, C.R., and Meo, T. 1997. Recognition of the E-C4 element from the C4 complement gene promoter by the upstream stimulatory factor-1 tran- scription factor. J. Immunol. 159: 6167-6183.

Galibert, M.-D., Yavuzer, U., Dexter, T.J., and Goding, C.R. 1999. Pax3 and regulation of the melanocyte-specific TRP-1 promoter. J. Biol. Chem. 274: 26894-26900.

Ganss, R., Montoliu, L., Monaghan, A.P., and Schutz, G. 1994a. A cell-specific enhancer far upstream of the mouse tyrosinase gene confers high level and copy number-related expression in transgenic mice. EMBO J. 13: 3083-3093.

Ganss, R., Schutz, G., and Beermann, F. 1994b. The mouse tyrosinase gene. Promoter modulation by positive and negative regulatory elements. J. Biol. Chem. 269: 29808-29816.

Giese, K., Cox, J., and Grosschedl, R. 1992. The HMG domain of lymphoid enhancer factor 1 bends DNA and facilitates assembly of functional nucleoprotein structures. Cell 69: 185195.

Hagiwara, M., Alberts, A., Brindle, P., Meinkoth, J., Feramisco, J., Deng, T., Karin, M., Shenolikar, S., and Montminy, M. 1992. Transcriptional attenuation following cAMP induction requires PP-1- mediated dephosphorylation of CREB. Cell 70: 105-113.

Hallsson, J.H., Favor, J., Hodgkinson, C., Glaser, T., Lamoreaux, L.M., Magnúsdóttir, R., Gunnarsson, N.G., Sweet, H.O., Copeland, N.G., Jenkins, N.A. et al. 2000. Genomic, transcriptional, and mutational analysis of the mouse microphthalmia locus. Genetics 155: 291-300.

Hemesath, T.J., Steingrimsson, E., McGill, G., Hansen, M.J., Vaught, J., Hodgkinson, C.A., Arnheiter, H., Copeland, N.G., Jenkins, N.A., and Fisher, D.E. 1994. Microphthalmia, a critical factor in melanocyte development, defines a discrete transcription factor family. Genes \& Dev. 8: 2770-2780.

Hemesath, T.J., Price, E.R., Takemoto, C., Badalian, T., and Fisher, D.E. 1998. MAP kinase links the transcription factor Microphthalmia to c-Kit signalling in melanocytes. Nature 391: 298-301.

Hill, H.Z. 1992. The function of melanin or six blind people examine an elephant. Bioessays 14: 49-56.

Hodgkinson, C.A., Moore, K.J., Nakayama, A., Steingrimsson, E., Copeland, N.G., Jenkins, N.A., and Arnheiter, H. 1993. Mutations at the mouse microphthalmia locus are associated with defects in a gene encoding a novel basic-helix-loophelix-zipper protein. Cell 74: 395-404.

Hollenbach, A.D., Sublett, J.E., McPherson, C.J., and Grosveld, G. 1999. The Pax3-FKHR oncoprotein is unresponsive to the Pax3-associated repressor hDaxx. EMBO J. 18: 3702-3711.

Hosoda, K., Hammer, R.E., Richardson, J.A., Baynash, A.G., Cheung, J.C., Giaid, A., and Yanagisawa, M. 1994. Targeted and natural (piebald-lethal) mutations of endothelin-B receptor gene produce megacolon associated with spotted coat color in mice. Cell 79: 1267-1276.

Huang, E., Nocka, K., Beier, D.R., Chu, T.Y., Buck, J., Lahm, H.W., Wellner, D., Leder, P., and Besmer, P. 1990. The hematopoietic growth factor KL is encoded by the Sl locus and is the ligand of the c-kit receptor, the gene product of the $\mathrm{W}$ locus. Cell 63: 225-233.

Huber, O., Korn, R., McLaughlin, J., Ohsugi, M., Herrmann, B.G., and Kemler, R. 1996. Nuclear localization of betacatenin by interaction with transcription factor LEF-1. Mech. Dev. 59: 3-10.

Hughes, M.J., Lingrel, J.B., Krakowsky, J.M., and Anderson, K.P. 1993. A helix-loop-helix transcription factor-like gene is located at the mi locus. J. Biol. Chem. 268: 20687-20690.

Ikeya, M., Lee, S.M.K., Johnson, J.E., McMahon, A.P., and Takada, S. 1997. Wnt signalling required for expansion of neural crest and CNS progenitors. Nature 289: 966-970.

Iordanov, M., Bender, K., Ade, T., Schmid, W., Sachsenmaier, C., Engel, K., Gaestel, M., Rahmsdorf, H.J., and Herrlich, P. 
1997. CREB is activated by UVC through a p38/Hog-1-dependent protein kinase. EMBO J. 16: 1009-1022.

Jackson, I.J. 1994. Molecular and developmental genetics of mouse coat color. Annu. Rev. Genet. 28: 189-217.

Jackson, I.J., Chambers, D.M., Budd, P.S., and Johnson, R. 1991. The tyrosinase-related protein-1 gene has a structure and promoter sequence very different from tyrosinase. Nucleic Acids Res. 19: 3799-3804.

Janknecht, R. and Hunter, T. 1996. Transcriptional control: Versatile molecular glue. Curr. Biol. 6: 951-954.

Jordan, S.A. and Jackson, I.J. 1998. Melanocortin receptors and antagonists regulate pigmentation and body weight. BioEssays 20: 603-606.

King, R., Weilbaecher, K.N., McGill, G., Cooley, E., Mihm, M., and Fisher, D.E. 1999. Microphthalmia transcription factor: A sensitive and specific melanocyte marker for Melanoma diagnosis. Am. J. Pathol. 155: 731-738.

Kissel, H., Timokhina, I., Hardy, M.P., Rothschild, G., Tajima, Y., Soares, V., Angeles, M., Whitlow, S.R., Manova, K., and Besmer, P. 2000. Point mutation in Kit receptor tyrosine kinase reveals essential roles for Kit signaling in spermatogenesis and oogenesis without affecting other Kit responses. EMBO I. 19: 1312-1326.

Kuhlbrodt, K., Herbarth, B., Sock, E., Hermans-Borgmeyer, I., and Wegner, M. 1998. Sox10, a novel transcriptional modulator in glial cells. J. Neurosci. 18: 237-250.

Lev, S., Blechman, J.M., Givol, D., and Yarden, Y. 1994. Steel factor and c-kit protooncogene: Genetic lessons in signal transduction. Crit. Rev. Oncogen. 5: 141-168.

Levenson, R. and Housman, D. 1981. Commitment: How do cells make the decision to differentiate. Cell 25: 5-6.

Levanon, D., Goldstein, R.E., Bernstein, Y., Tang, H., Goldenberg, D., Stifani, S., Paroush, Z., and Groner, Y. 1998. Transcriptional repression by AML1 and LEF-1 is mediated by the TLE/Groucho corepressors. Proc. Natl. Acad. Sci. 95: 11590-11595.

Lister, J.A., Robertson, C.P., Lepage, T., Johnson, S.L., and Raible, D.W. 1999. nacre encodes a zebrafish microphthalmia-related protein that regulates neural-crest-derived pigment cell fate. Development 126: 3757-3767.

Lowings, P., Yavuzer, U., and Goding, C.R. 1992. Positive and negative elements regulate a melanocyte-specific promoter. Mol. Cell. Biol. 12: 3653-3662.

Mackenzie, M.A., Jordan, S.A., Budd, P.S., and Jackson, I.J. 1997. Activation of the receptor tyrosine kinase Kit is required for the proliferation of melanoblasts in the mouse embryo. Dev. Biol. 192: 99-107.

Magnaghi, P., Roberts, C., Lorain, S., Lipinski, M., and Scambler, P.J. 1998. HIRA, a mammalian homologue of Saccharomyces cerevisiae transcriptional co-repressors, interacts with Pax3. Nat. Genet. 20: 74-77.

Marshall, C.J. 1995. Specificity of receptor tyrosine kinase signaling: Transient versus sustained extracellular signal-regulated kinase activation. Cell 80: 179-185.

Mayer, T.C. 1973. The migratory pathway of neural crest cells into the skin of mouse embryos. Dev. Biol. 34: 39-46.

Molenaar, M., van de Wetering, M., Oosterwegel, M., PetersonMaduro, J., Godsave, S., Korinek, V., Roose, J., Destree, O., and Clevers, H. 1996. XTcf-3 transcription factor mediates beta-catenin-induced axis formation in Xenopus embryos. Cell 86: 391-399.

Moore, K.J. 1995. Insight into the microphthalmia gene. Trends Genet. 11: 442-448.

Mountjoy, K.G., Robbins, L.S., Mortrud, M.T., and Cone, R.D. 1992. The cloning of a family of genes that encode the melanocortin receptors. Science 257: 1248-1251.
Munemitsu, S., Albert, I., Souza, B., Rubinfeld, B., and Polakis P. 1995. Regulation of intracellular beta-catenin levels by the adenomatous polyposis coli (APC) tumor-suppressor protein. Proc. Natl. Acad. Sci. 92: 3046-3050.

Nakayama, A., Nguyen, M.T., Chen, C.C., Opdecamp, K., Hodgkinson, C.A., and Arnheiter, H. 1998. Mutations in microphthalmia, the mouse homolog of the human deafness gene MITF, affect neuroepithelial and neural crest-derived melanocytes differently. Mech. Dev. 70: 155-166.

Nishikawa, S., Kusakabe, M., Yoshinaga, K., Ogawa, M., Hayashi, S.-I., Kunisada, T., Era, T., Sakakura, T., and Nishikawa, S.-I. 1991. In utero manipulation of coat color formation by a monoclonal anti-c-kit antibody: Two distinct waves of ckit-dependency during melanocyte development. EMBO $\mathrm{J}$. 10: 2111-2118.

Nishita, M., Hasimoto, M.K., Ogata, S., Laurent, M.N., Ueno, N., Shibuyu, H., and Cho, K.W.Y. 2000. Interaction between Wnt and TGF- $\beta$ signalling pathways during formation of Speman's organizer. Nature 403: 781-785.

Opdecamp, K., Nakayama, A., Nguyen, M.T., Hodgkinson, C.A., Pavan, W.J., and Arnheiter, H. 1997. Melanocyte development in vivo and in neural crest cell cultures: Crucial dependence on the Mitf basic-helix-loop-helix-zipper transcription factor. Development 124: 2377-2386.

Parichy, D.M., Rawls, J.F., Pratt, S.J., Whitfield, T.T., and Johnson, S.L. 1999. Zebrafish sparse corresponds to an orthologue of c-kit and is required for the morphogenesis of a subpopulation of melanocytes, but is not essential for hematopoiesis or primordial germ cell development. Development 126: 3425-3436.

Pingault, V., Bondurand, N., Kuhlbrodt, K., Goerich, D.E., Préhu, M.-O., Puliti, A., Herbarth, B., Hermans-Borgmeyer, I., Legius, E., Matthijs, G. et al. 1998. SOX10 mutations in patients with Waardenburgs-Hirschprung disease. Nat. Genet. 18: 171-173.

Planque, N., Turque, N., Opdecamp, K., Bailly, M., Martin, P., and Saule, S. 1999. Expression of the microphthalmia-associated basic helix-loop-helix leucine zipper transcription factor $\mathrm{Mi}$ in avian neuroretina cells induces a pigmented phenotype. Cell Growth Differ. 10: 525-536.

Porter, S.D. and Meyer, C.J. 1994. A distal tyrosinase upstream element stimulates gene expression in neural crest-derived melanocytes of transgenic mice: Position-independent and mosaic expression. Development 120: 2103-2111.

Potterf, B., Arnheiter, H., and Pavan, W. 2000. Transcription factor heirarchy in Waardenburg syndrome: Synergistic regulation of Mitf expression by Sox10 and Pax3. (in press).

Price, E.R., Ding, H.-F., Badalian, T., Bhattacharya, S., Takemoto, C., Yao, T.-P., Hemesath, T.J., and Fisher, D.E. 1998a. Lineage-specific signalling in melanocytes: c-Kit stimulation recruits p300/CBP to Microphthalmia. J. Biol. Chem. 273: 17983-17986.

Price, E.R., Horstmann, M.A., Wells, A.G., Weilbeacher, K.N., Takemoto, C.M., Landis, M.W., and Fisher, D.E. 1998b. $\alpha$-Melanocyte-stimulating hormone signaling regulates expression in microphthalmia, a gene deficient in Waardenburg syndrome. J. Biol. Chem. 273: 33042-33047.

Puffenberger, E.G., Hosoda, K., Washington, S.S., Nakao, K., deWit, D., Yanagisawa, M., and Chakravart, A. 1994. A missense mutation of the endothelin- $\beta$ receptor gene in multigenic Hirschsprung's disease. Cell 79: 1257-1266.

Roose, J., Molenaar, M., Peterson, J., Hurenkamp, J., Brantjes, H., Moerer, P., van de Wetering, M., Destree, O., and Clevers, H. 1998. The Xenopus Wnt effector XTcf-3 interacts with Groucho-related transcriptional repressors. Nature 395: 608-612. 
Rubinfeld, B., Souza, B., Albert, I., Muller, O., Chamberlain, S.H., Masiarz, F.R., Munemitsu, S., and Polakis, P. 1993. Association of the APC gene product with beta-catenin. Science 262: 1731-1734.

Rubinfeld, B., Albert, I., Porfiri, E., Fiol, C., Munemitsu, S., and Polakis, P. 1996. Binding of GSK3beta to the APC-betacatenin complex and regulation of complex assembly. Science 272: 1023-1026.

Rubinfeld, B., Robbins, P., El-Gamil, M., Albert, I., Porfiri, E., and Polakis, P. 1997. Stabilization of beta-catenin by genetic defects in melanoma cell lines. Science 275: 1790-1792.

Sato, S., Roberts, K., Gambino, G., Cook, A., Kouzarides, T., and Goding, C.R. 1997. CBP/p300 as a co-factor for the Microphthalmia transcription factor. Oncogene 14: 3083-3092.

Satoh, S., Daigo, Y., Furukawa, Y., Kato, T., Miwa, N., Nishiwaki, T., Kawasoe, T., Ishiguro, H., Fujita, M., Tokino, T. et al. 2000. AXIN1 mutations in hepatocellular carcinomas, and growth suppression in cancer cells by virus-mediated transfer of AXIN1. Nat. Genet. 24: 245-250.

Schild-Poulter, C., Sassone-Corsi, P., Granger-Schnarr, M., and Schnarr, M. 1996. Nucleosome assembly on the human c-fos promoter interferes with transcription factor binding. Nucleic Acids Res. 24: 4751-4758.

Shibata, K., Muraosa, Y., Tomita, Y., Tagami, H., and Shibahara, S. 1992. Identification of a cis-acting element that enhances the pigment cell-specific expression of the human tyrosinase gene. J. Biol. Chem. 267: 20584-20588.

Shin, M.K., Levorse, J.M., Ingram, R.S., and Tilghman, S.M. 1999. The temporal requirement for endothelin receptor-B signalling during neural crest development. Nature 402: 496-501.

Southard-Smith, E.M., Kos, L., and Pavan, W. 1998. Sox10 mutation disrupts neural crest development in Dom Hirschprung mouse model. Nat. Genet. 18: 60-64.

Steel, K.P. and Barkway, C. 1989. Another role for melanocytes: Their importance for stria vascularis development in the mammalian innner ear. Development 107: 453-463.

Steingrímsson, E., Moore, K.J., Lamoreaux, M.L., FerréD'Amaré, A.R., Burley, S.K., Sanders Zimring, D.C., Skow, L.C., Hodgkinson, C.A., Arnheiter, H., Copeland, N.G. et al. 1994a. Molecular basis of mouse microphthalmia (mi) mutations helps explain their developmental and phenotypic consequences. Nat. Genet. 8: 256-263.

Stokoe, D., Stephens, L.R., Copeland, T., Gaffney, P.R., Reese, C.B., Painter, G.F., Holmes, A.B., McCormick, F., and Hawkins, P.T. 1997. Dual role of phosphatidyleinositol-3,4,5-triphosphate in the activation of protein kinase B. Science 277: $567-570$.

Tachibana, M. 1999. Sound needs sound melanocytes to be heard. Pigment Cell Res. 12: 344-354.

Tachibana, M., Takeda, K., Nobukuni, Y., Urabe, K., Long, J.E., Meyers, K.A., Aaronson, S.A., and Miki, T. 1996. Ectopic expression of MITF, a gene for Waardenburgs syndrome type 2 , converts fibroblasts to cells with melanocyte characteristics. Nat. Genet. 14: 50-54.

Takeda, K., Takemoto, C., Kobayashi, I., Watanabe, A., Nobukuni, Y., Fisher, D.E., and Tachibana, M. 2000a. Ser298 of MITF, a mutation site in Waardenburg syndrome type 2, is a phosphorylation site with functional significance. Hum. Mol. Genet. 9: 125-132.

Takeda, K., Yasumoto, K.-I., Takada, R., Takada, S., Watanabe, K.-I., Udono, T., Saito, H., Takahashi, K., and Shibahara, S. 2000b. Induction of melanocyte-specific microphthalmia-associated transcription factor by Wnt3a. J. Biol. Chem. (in press).

Tan, Y., Rouse, J., Zhang, A., Cariati, S., Cohen, P., and Comb,
M.J. 1996. FGF and stress regulate CREB and ATF-1 via a pathway involving p38 MAP kinase and MAPKAP kinase-2. EMBO J. 15: 4629-4642.

Tassabehji, M., Read, A.P., Newton, V.E., Harris, R., Balling, R., Gruss, P., and Strachan, T. 1992. Waardenburg's syndrome patients have mutations in the human homologue of the Pax-3 paired box gene. Nature 355: 635-636.

Tassabehji, M., Read, A.P., Newton, V.E., Patton, M., Gruss, P., Harris, R., and Strachan, T. 1993. Mutations in the PAX3 gene causing Waardenburg syndrome type 1 and type 2. Nat. Genet. 3: 26-30.

Tassabehji, M., Newton, V.E., and Read, A.P. 1994. Waardenburg syndrome type 2 caused by mutations in the human microphthalmia (MITF) gene. Nat. Genet. 8: 251-255.

Tetsu, O. and McCormick, F. 1999. Beta-catenin regulates expression of cyclin D1 in colon carcinoma cells. Nature 398: 422-426.

Tong-Chuan, H., Sparks, A.B., Rago, C., Hermeking, H., Zawel, L., da Costa, L.T., Morin, P.J., Vogelstein, B., and Kinzler, K.W. 1998. Identification of $c-M y c$ as a target of the APC pathway. Science 281: 1509-1512.

Tsujimura, T., Hashimoto, K., Morii, E., Tunio, G.M., Tsujino, K., Kondo, T., Kanakura, Y., and Kitamura, Y. 1997. Involvement of transcription factor encoded by the mouse mi locus (MITF) in apoptosis of cultured mast cells induced by removal of interleukin-3. Am. J. Pathol. 151: 1043-1051.

Turque, N., Martin, P., Planque, N., Bailly, M., Begue, A., Stehelin, D., and Saule, S. 1996. Characterization of a new melanocyte-specific gene (QNR-71) expressed in v-myc transformed quail neuroretina. EMBO J. 15: 3338-3350.

Udono, T., Yasumoto, K., Takeda, K., Amae, S., Watanabe, K., Saito, H., Fuse, N., Tachibana, M., Takahashi, K., Tamai, M. et al. 2000. Structural organization of the human microphthalmia-associated transcription factor gene containing four alternative promoters. Biochim. Biophys. Acta. 1491: 205219.

Verastegui, C., Bertolotto, C., Bille, K., Abbe, P., Ortonne, J.P., and Ballotti, R. 2000. TFE3, a transcription factor homologous to microphthalmia, is a potential transcriptional activator of tyrosinase and Tyrp1 genes. Mol. Endocrinol. 14: 449-456.

Vossler, M.R., Yao, H., Pan, M.-G., Rim, C.S., and Stork, P.J.S. 1997. cAMP activates MAP kinase and Elk-1 through a BRaf- and Rap1-dependent pathway. Cell 89: 73-82.

Wadzinski, B.E., Wheat, W.H., Jaspers, S., Peruski, L.F., Jr., Lickteig, R.L., Johnson, G.L., and Klemm, D.J. 1993. Nuclear protein phosphatase $2 \mathrm{~A}$ dephosphorylates protein kinase Aphosphorylated CREB and regulates CREB transcriptional stimulation. Mol. Cell. Biol. 13: 2822-2834.

Watanabe, A., Takeda, K., Ploplis, B., and Tachibana, M. 1998. Epistatic relationship between Waardenburg syndrome genes MITF and PAX3. Nat. Genet. 18: 283-286.

Wehrle-Haller, B. and Weston, J.A. 1995. Soluble and cell-bound forms of steel factor activity play distinct roles in melanocyte precursor dispersal and survival on the lateral neural crest migration pathway. Development 121: 731-742.

Williams, D.E., Eisenmann, J., Baird, A., Rauch, C., Van Ness, K., March, C.J., Park, L.S., Martin, U., Mochizuki, D.Y., Boswell, H.S.et al. 1990. Identification of a ligand for the c-kit proto-oncogene. Cell 63: 167-174.

Wittbrodt, J., Adam, D., Malitschek, B., Maueler, W., Raulf, F., Telling, A., Robertson, S.M., and Schartl, M. 1989. Novel putative receptor tyrosine kinase encoded by the melanomainducing Tu locus in Xiphophorus. Nature 341: 415-421.

Wolfe, H.G. and Coleman, D.L. 1964. Mi-spotted: A mutation in the mouse. Genet Res. 5: 432-440. 
Wu, M., Hemesath, T.J., Takemoto, C.M., Horstmann, C.A., Wells, A.G., Price, E.R., Fisher, D.Z., and Fisher, D.E. 2000. c-Kit triggers dual phosphorylations, which couple activation and degradation of the essential melanocyte factor Mi. Genes \& Dev. 14: 301-312.

Xing, J., Ginty, D.D., and Greenberg, M.E. 1996. Coupling of the RAS-MAPK pathway to gene activation by RSK2, a growth factor-regulated CREB kinase. Science 273: 959-963.

Xing, J., Kornhauser, J.M., Xia, Z., Thiele, E.A., and Greenberg, M.E. 1998. Nerve growth factor activates extracellular signal-regulated kinase and p38 mitogen-activated protein kinase pathways to stimulate CREB serine 133 phosphorylation. Mol. Cell. Biol. 18: 1946-1955.

Xu, W., Gong, L., Haddad, M.M., Bischof, O., Campisi, J., Yeh, E.T., and Medrano, E.E. 2000. Regulation of microphthalmia-asociated transcription factor Mitf protein levels by association with the ubiquitin-conjugating enzyme hUBC9. Exp. Cell Res. 255: 135-143.

Yajima, I., Sato, S., Kimura, T., Yasumoto, K., Shibahara, S., Goding, C.R., and Yamamoto, H. 1999. An L1 element intronic insertion in the black-eyed white $\left(\right.$ Mitf $\left.^{\text {mi-bw }}\right)$ gene: The loss of a single Mitf isoform responsible for the pigmentary defect and inner ear deafness. Hum. Mol. Genet. 8: $1431-1441$.

Yasumoto, K., Yokoyama, K., Shibata, K., Tomita, Y., and Shibahara, S. 1994. Microphthalmia-associated transcription factor as a regulator for melanocyte-specific transcription of the human tyrosinase gene. Mol. Cell. Biol. 14: 8058-8070.

Yasumoto, K.-I., Amae, S., Udono, T., Fuse, N., Takeda, K., and Shibahara, S. 1998. A big gene linked to small eyes: Many promoters make light work. Pigment Cell Res. 11: 329-336.

Yavuzer, U. and Goding, C.R. 1994. Melanocyte-specific gene expression: Role of repression and identification of a melanocyte-specific factor, MSF. Mol. Cell. Biol. 14: 3494-3503.

Yavuzer, U., Keenan, E., Lowings, P., Vachtenhein, J., Currie G., and Goding, C.R. 1995. The microphthalmia gene product interacts with the retinoblastoma protein in vitro and is a target for deregulation of melanocyte-specific transcription. Oncogene 10: 123-134.

Yokoyama, K., Yasumoto, K., Suzuki, H., and Shibahara, S. 1994. Cloning of the human DOPAchrome tautomerase/tyrosinase-related protein 2 gene and identification of two regulatory regions required for its pigment cell-specific expression. J. Biol. Chem. 269: 27080-27087.

Yuh, C.H., Bolouri, H., and Davidson, E.H. 1998. Genomic cisregulatory logic: Experimental and computational analysis of a sea urchin gene. Science 279: 1896-1902.

Zorn, A.M., Barish, G.D., Williams, B.O., Lavender, P., Klymkowsky, M.W., and Varmus, H.E. 1999. Regulation of Wnt signaling by Sox proteins: XSox17 alpha/beta and XSox3 physically interact with beta-catenin. Mol. Cell. 4: $487-498$

Zsebo, K.M., Williams, D.A., Geissler, E.N., Broudy, V.C., Martin, F.H., Atkins, H.L., Hsu, R.-Y., Birkett, N.C., Okino, K.H., Murdock, D.C. et al. 1990. Stem cell factor is encoded at the SI locus of the mouse and is the ligand for the c-kit tyrosine kinase receptor. Cell 63: 213-224. 


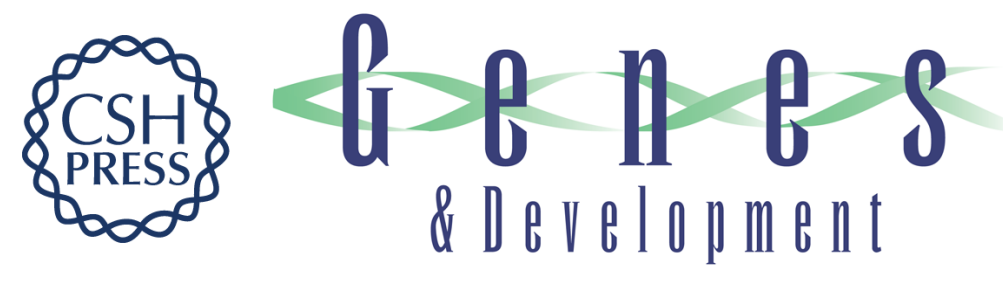

\title{
Mitf from neural crest to melanoma: signal transduction and transcription in the melanocyte lineage
}

\author{
Colin R. Goding
}

Genes Dev. 2000, 14:

Access the most recent version at doi:10.1101/gad.14.14.1712

$\begin{array}{ll}\text { References } & \begin{array}{l}\text { This article cites } 130 \text { articles, } 55 \text { of which can be accessed free at: } \\ \text { http://genesdev.cshlp.org/content/14/14/1712.full.html\#ref-list-1 }\end{array}\end{array}$

License

Email Alerting

Receive free email alerts when new articles cite this article - sign up in the box at the top Service right corner of the article or click here.

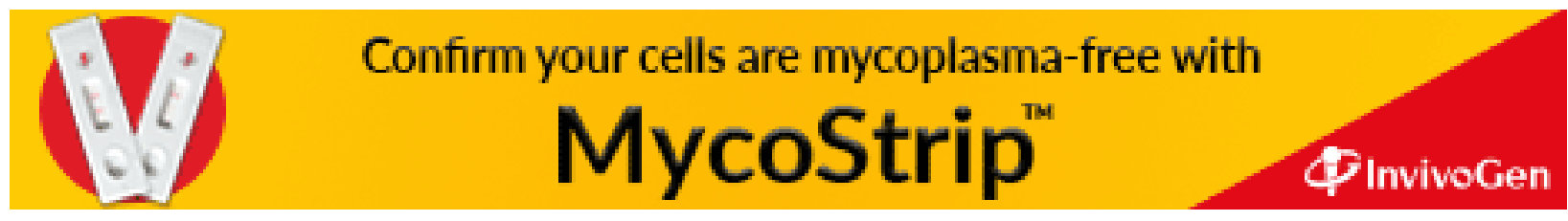

